\title{
Homologs of the mouse Brachyury gene are involved in the specification of posterior terminal structures in Drosophila, Tribolium, and Locusta
}

\author{
Andreas Kispert, ${ }^{1,3}$ Bernhard G. Herrmann, ${ }^{1}$ Maria Leptin, ${ }^{2,4}$ and Rolf Reuter ${ }^{2,5}$ \\ Max-Planck-Institut fur Entwicklungsbiologie, ${ }^{1}$ Abteilung Biochemie, ${ }^{2}$ Abteilung Zellbiologie, D-72076 Tübingen, Germany
}

\begin{abstract}
The Brachyury (T) gene is required for notochord differentiation in vertebrates. We have identified a Drosophila gene, the $T$-related gene ( $T r g$ ), with high similarity to $T$ within a stretch of $\sim 200$ amino acids, the DNA-binding domain of $T$. $T$ rg is expressed throughout embryogenesis, first at the blastoderm stage in the hindgut primordium under the control of the terminal gap genes $t l l$ and $h k b$, and then until the end of embryogenesis in the differentiating hindgut. Drosophila embryos deficient for Trg do not form the hindgut, a phenotype that can be rescued by a Trg transgene. Thus, a common feature of $T$ and $\operatorname{Tr} g$ is their requirement in specifying the development of a single embryonic structure. Homologs of $\mathrm{Trg}$ are also expressed in the developing hindgut of Tribolium and Locusta embryos suggesting a highly conserved function of $T$ rg in insects. This conservation and the high similarity of $T$ and $T r g$ raise the question of a common evolutionary origin of the hindgut of insects and the notochord of chordates.
\end{abstract}

[Key Words: Drosophila; Brachyury; Locusta; Tribolium; gut; proctodeum]

Received May 16, 1994; revised version accepted July 25, 1994.

With the molecular characterization of genes involved in animal development it has become increasingly obvious that some gene families appear to have retained their function in a wide range of animal species. The best example of such a gene family is the Hox gene complex characterized by the clustered genomic arrangement of homeo box-containing genes (for review, see McGinnis and Krumlauf 1992). The Hox genes provide positional information along the anteroposterior body axis during development, as revealed by genetic analysis in Drosophila, mouse, and Caenorhabditis elegans (for review, see Slack et al. 1993\}. Homologs of other genes, first functionally characterized in the embryonic development of Drosophila, are now being cloned and characterized in chordates and other animal classes. In general, the molecules, or at least their functionally important domains, have been highly conserved during evolution, but the developmental processes in which they are involved are often more diverged than in the case of the Hox genes. For example, the numerous engrailed $\mid e n\}$ and wingless (wg or wnt) homologs expressed during vertebrate development (Patel et al. 1989a; Davis et al. 1991; McMahon 1992) do not appear to function in the

\footnotetext{
Present addresses: ${ }^{3}$ Harvard University, The Biological Laboratories, Cambridge, Massachusetts 02138 USA; ${ }^{4}$ Universität zu Köln, Institut für Genetik, D-50931 Köln, Germany.
}

${ }^{5}$ Corresponding author. establishment of segment boundaries as they do in Drosophila. However, in a specific step during brain development the molecules interact in a way analogous to their interaction in Drosophila, with wg being required for the maintenance of en expression (McMahon et al. 1992). In some developmental processes, single molecules or structural motifs have been conserved during evolution, whereas entire regulatory chains of genes are conserved in other cases.

One important gene for the development of chordates, for which no homolog has yet been described in Drosophila or other invertebrates, is the Brachyury $(T)$ gene. Genetic analysis in mouse and in zebrafish revealed that $T$ acts in the differentiation of the notochord and in the generation of mesendoderm during axis elongation (Beddington et al. 1992 and references therein; Halpern et al. 1993). T genes have been molecularly characterized for a number of chordates (Herrmann et al. 1990; Smith et al. 1991; Schulte-Merker et al. 1992; Yasuo and Satoh 1994). They are highly similar within a stretch of $>200$ amino acids that have been shown to be necessary and sufficient for specific DNA binding (Kispert and Herrmann 1993). Because the genes are expressed in homologous structures in the various species and have the same function in axial development in two distantly related vertebrates they are certainly also functional homologs.

We are interested in the phylogenetic origin of the $T$ 
genes and wished to determine whether molecules closely related to $T$ might exist in animal classes other than the chordates, particularly in the arthropods. As an initial tool we used an antibody directed against the amino terminus of the mouse T protein (Kispert and Herrmann 1993, 1994). This part of the protein is sufficiently similar within the various $T$ genes to allow the antibody to cross-react with both the Xenopus and zebrafish $T$ gene products. Surprisingly, the antibody detected an antigen specifically expressed in the Drosophila embryo. The molecular cloning and sequencing of the gene encoding this antigen revealed a high structural similarity to the DNA-binding domain of the vertebrate $T$ genes leading to the designation Drosophila $T$-related gene $(\operatorname{Trg})$. Because $\operatorname{Trg}$ is exclusively expressed in the posterior terminal region of the Drosophila embryo, we wish to give a brief synopsis of the development of this body region.

The zygotic transcription factors, tailless $(t 11)$ and huckebein $(h k b)$, are required to specify the terminal structures that originate from the region located posterior to the primordia of the segmented body (Strecker et al. 1988; Casanova 1990; Weigel et al. 1990|. $h k b$ is expressed during the blastoderm stage at the posterior pole in the posterior midgut primordium (Brönner and Jäckle 1991) and determines the posterior midgut (Weigel et al. 1990). tll is expressed during the blastoderm stage in a larger domain that includes the $h k b$ domain and also comprises the primordium of the proctodeum (Pignoni et al. 1990). The proctodeum invaginates with the posterior midgut primordium and forms hindgut and Malpighian tubules. Both processes, the invagination and the determination of the proctodeal structures, depend on tll. tll and $h k b$ act as gap genes, that is, they establish the posterior terminal region in the body plan and repress the expression of other gap genes acting in trunk specification. In embryos lacking $h k b$, the posterior midgut is deleted, and in embryos lacking tll posterior abdominal segments, the proctodeum and a minor part of the posterior midgut are not formed.

$h k b$ and tll must act through a set of downstream genes to specify the organs dependent on their activities. Such a gene is fork head $(f k h)$, which is activated by both $h k b$ and $t l l$ in the primordium of posterior midgut and proctodeum (Weigel et al. 1989a, 1990). $f k h$ seems to act as a homeotic gene and promotes development of terminal, as opposed to segmental, structures (Jürgens and Weigel 1988). A candidate downstream gene for $h k b$ is serpent (srp), which also acts as a homeotic gene and specifies the development of endodermal posterior midgut as opposed to ectodermal hindgut (Reuter 1994). In addition, genes are known that are required for the correct positioning of the Malpighian tubules (Krüppel; Harbecke and Janning 1989; Skaer 1993) and for the differentiation of the anal pads [caudal (cad); Macdonald and Struhl 1986]. However, several other genes required for the partitioning of the terminal region must exist. Our results show that $\operatorname{Tr} g$, which is involved in the specification of hindgut and anal pads, is a target for regulation by $t l l$ and $h k b$.

\section{Results}

A Drosophila embryonic cDNA library was screened with the conserved region of a mouse $T$ cDNA using low stringency hybridization conditions. The strongly hybridizing clones harbored a $2.6-\mathrm{kb}$ cDNA as the largest insert, which we assume to represent a full-length cDNA. The insert includes the poly(A) tract at the $3^{\prime}$ end and a long $5^{\prime}$-untranslated region that is blocked in all three reading frames by two or three stop codons. The nucleotide sequence of this cDNA is presented in Figure 1. It is $2630 \mathrm{bp}$ in length and contains a potential open reading frame of $2163 \mathrm{bp}$. The putative start codon (position $337-339$ ) is flanked by a sequence resembling the consensus sequence of translation start sites in Drosophila (Cavener 1987).

\section{Trg contains a highly conserved T-domain}

The putative $\operatorname{Trg}$ protein sequence comprises 721 amino acids. The prominent feature of this sequence is a stretch of 200 amino acids (Fig. 2), which shows extensive similarity with a domain found in the amino terminus of the chordate $T$ gene products $\mathrm{T}, \mathrm{Xbra}, \mathrm{Zf}-\mathrm{T}$, and As- $\mathrm{T}$ (Herrmann et al. 1990; Smith et al. 1991; Schulte-Merker et al. 1992; Yasuo and Satoh 1994). This T-domain has been shown to confer specific DNA binding (Kispert and Herrmann 1993). Another Drosophila protein, the product of the gene optomotor-blind (omb), also contains a T-domain (Pflugfelder et al. 1992). However, the similarity of $\mathrm{Omb}$ to Trg and the chordate gene products is only moderate (Table 1). In addition, Omb is distinguished from the other proteins of the group by several insertions within the T-domain (Fig. 2). Although the T-domains of Trg and Omb share a particular feature fa stretch of strong divergence from the vertebrate proteins after the seventh amino acid of the T-domain), the T-domain of Trg is much more similar to the chordate $T$-gene products than to Omb (Table 1). Outside the T-domain there is only a limited similarity between the products of the chordate $T$ genes and none between the chordate proteins and Trg or Omb.

\section{Trg is expressed in the posterior terminal region of the Drosophila embryo}

The expression of $\operatorname{Tr} g$ commences at the beginning of nuclear cycle 14 in the posterior terminal region from $\sim 20$ to $0 \%$ egg length (Fig. 3A,B). During cellularization, $\operatorname{Trg}$ expression recedes from the posterior pole (Fig. $3 \mathrm{C}$ ) and becomes confined to a ring of cells of which the ventral cells form the posterior part of the ventral furrow (Fig. 3E), whereas the dorsal and lateral cells appear to constitute the primordium of most of the proctodeum and probably of the anal pads. These dorsal and lateral cells become internalized by the amnioproctodeal invagination during gastrulation (Fig. 3F,G). During germband extension the proctodeum continues to express $\operatorname{Tr} g$, but the expression disappears in the adjacent mesoderm that has originated from the posterior end of the 
1 GAT CAT TAG CTC GGG AAC GGT GGC BAC GCA AAC ACA CGA TCG GCG GCA GCG CTA AAC TCC AAT CTC 66 GAA TCT CGA CTC GAA TCA AAT ATC TTG AAA TCT TTG AAA ACA AAT TTC ACG CGG CTG TAT CTT CCC ACT TGA 139 ATC TGA ACT CAT ACG ATA GTG ATC CTT GAT AAA GTG AAC CCT CCA GGG AAT TAG TGC TAT AAA AGT GCG TGA 211 TTT GGC AGT GTT GCG TAT TCA ACT GAA ATC TAA ATC TAA ACC TAA ACC ATC TTC ATA AGG AGT TTA CCA CTG

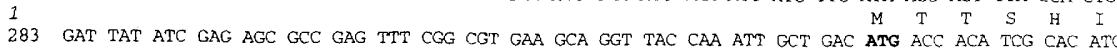

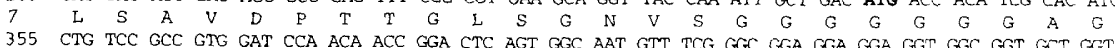
31 G G A $G$ S G S P $Q$ G H V G T AAT GTT TCG GGC GGA GGA GGA GGT GGC GGT GCT GGT 427 GGC GGT GCT GGC AGT GGT TCG CCA CAG CAT GTG ACC CAC AAT GGA CAC GGG CAT GGT CAC GGG CTG GGG GGC $\begin{array}{llllllllllllllllllllllllll}55 & V & A & A & V & S & G & G & G & A & S & V & S & G & N & G & G & H & R & V & V & G & G & A & G\end{array}$ 79 S P N E L D R N L R I S L D D R E L W L R F Q N 571 AGT CCC AAT GAA CTG GAT CGC AAT CTG CGC ATC TCG CTG GAT GAT CGG GAG CTC TGG CTG CGT TTC CAG AAT

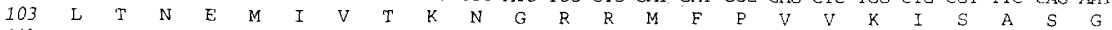
643 CTC ACC AAC GAG ATG ATC GTC ACC AAA AAC GGC AGG CGC ATG TTTC CCG GTC GTG AAG ATC AGT GCC TCC GGT

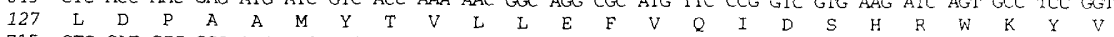
715 CTG GAT CCC GCC GCC ATG TAC ACC GTC CTC CTG GAG TTC GTC CAG ATC GAC TCA CAT CGC TGG AAG TAC GTC 151 N G G E W V V P G G K A 787 AAC GGT GAA TGG GTT CCT GGT GGC AAG GCA GAG GTT CCC CCG TCA AAT CCC ATC TAT GTA CAC CCC GAG TCS
175
$\mathrm{P}$

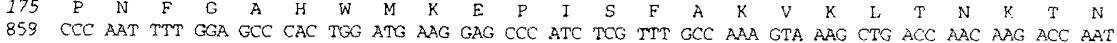

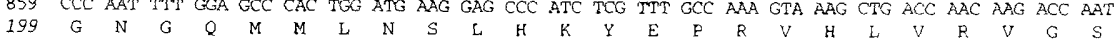

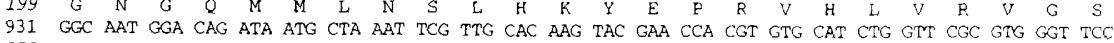

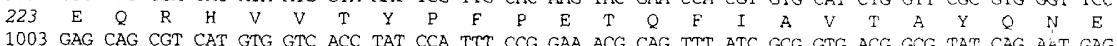
1003 GAG CAG CGT CAT GTG GTC ACC TAT CCA TTT CCG GAA ACG CAG TTT ATC GCG GTG ACG GCG TAT CAG AAT GAG

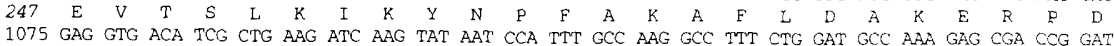

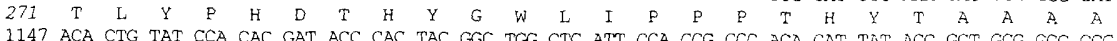
1147 ACA CTG TAT CCA CAC GAT ACC CAC TAC GGC TGG CTC ATT CCA CCG CCC ACA CAT TAT ACG GCT GCG GCG GCO

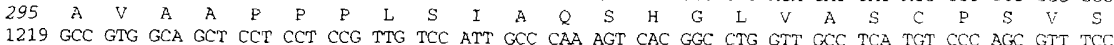
$\begin{array}{lllllllllllllllllllllllll}319 & S & A & G & S & V & G & P & S & S & G & G & S & C & D & R & Y & G & S & S & L & S & S & R & S\end{array}$

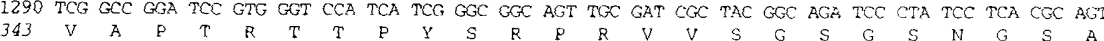
1363 GTC GCA CCC ACT CGC ACC ACA CCG TAC AGT CGA CCC AGG GTC GTT TCC GGE TCC GGA TCA AAT GGC AGT GCC $\begin{array}{lllllllllllllllllllllllll}367 & G & N & A & S & S & T & S & P & Q & P & P & S & A & P & Q & T & P & T & S & L & H & S & T & S\end{array}$ 1435 GGC AAT GCC TCG TCC ACA TCG CCG CAG CCG CCG TCG GCT CCA CAA ACG CCC ACC AGC CTCG CAC TCC ACG TCC

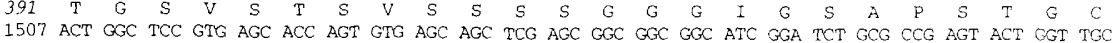

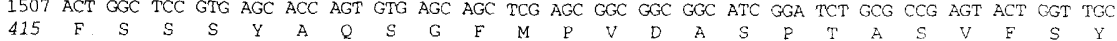

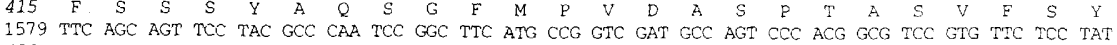

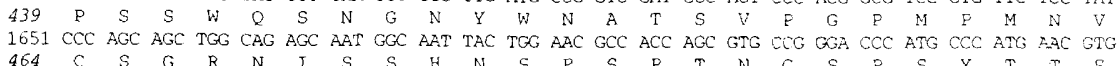

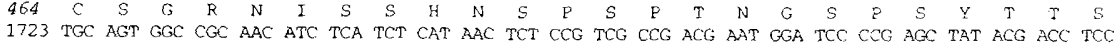

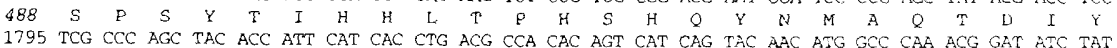
1795 TCG CCC AGC TAC ACC ATT CAT CAC CTG ACG CCA CAC AGT CAT CAG TAC AAC ATG GCC CAA ACG GAT ATC TAT 1867 GGA ACC GGA GTG GGC GTT GGG GGC GGG GCA GGA ACA ACG GGA TCC CCG Q

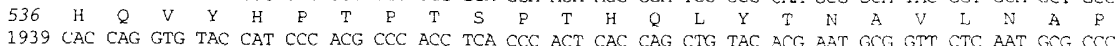
\begin{tabular}{lllllllllllllllllllllllll}
560 & $S$ & $A$ & $L$ & $S$ & $Y$ & $S$ & $A$ & $S$ & $G$ & $W$ & $H$ & $N$ & $G$ & $S$ & $G$ & $A$ & $E$ & $Y$ & $G$ & $L$ & $Y$ & $Q$ & $N$ & $A$ \\
\hline
\end{tabular} 2011 TCG GCG CTA AGC TAT TCC GCC AGT GGT TGG CAC AAT GGA TCC GGG GCG GAG TAC GGA CTS TAC CAG AAC GCT 584 A

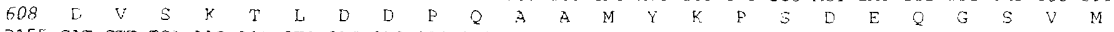
2155 GAT GTT TCA AAG ACA CTG GAC GAC CCC CAG GCT GCC ATG TAC AAG CCG AGE GAT GAG CAG GEC TCO GTC ATA

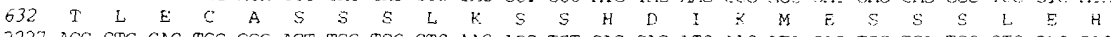
2227 ACG CTG GAG TGC GCC AGT TCC TCC CTG AAG AGC TCT CAC GAC ATC AAG ATA GAG TCC TCA TCC CTC GZG CAC 656 A $G$ E R G T V G G S A A V V S V P T A V V N S A 2999 GCC GGG GAA CGG GGC ACT GTT GGC GGT GGA GCT GCC GTG GTC TCG GTS CDA ACC GCC GTC GTG AAT GLA GCT

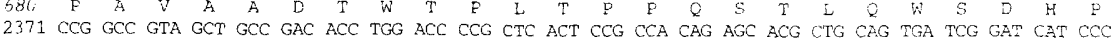
2371 CCG GCC GTA GCT GCC GAC ACC TGG ACC CCG CTC ACT CCG CCA CAG AGC ACG CIG CAG TGA TCG GATP CAT CCC 2443 ACG GAT AAA CCC ACA GCC TTT AGA CGC ATG ACC CCC CTG GAT GTT CGR TCG AGT TAG AAA TAA ACG CCC TAT 2515 GTT AGT AAC GCT ATT AGT AAA GCA CAC CCA ATC GCA ATC GCA CCT ATT GTA GAA CTA TCT GTA CGC TGT AAA 2587 CAA TCT CCI ATA ABG TCG TAA TCA AAC TAT GCA AAA AAA AAA AA 2630
Figure 1. The nucleotide and putative protein sequence of $\operatorname{Trg}$. The sequence of the cDNA 1 of the $\operatorname{Tr} g$ gene encompasses 2630 bp including 13 adenylyl residues at the $3^{\prime}$ end. The ATG at position 337-339 represents the putative start codon of the Trgencoded protein and is indicated in boldface type. A glycine-rich stretch is located between amino acids 15 and 78 . The middle of the protein (amino acids $316-492$ ) is significantly enriched $(36 \%)$ for serines and threonines. Possible polyadenylation signals at positions 2501, 2595, and 2606 are underlined. ventral furrow (data not shown; cf. Fig. 4B). The expression is maintained in the hindgut and the anal pads until the end of embryogenesis (Fig. 3H; data not shown). The other proctodeal derivative, the Malpighian tubules, and the region from which the Malpighian tubules evaginate (the connection between the posterior midgut and hindgut) are devoid of $T r g$ expression. There is also no expression in the mesoderm surrounding the hindgut.

The very high similarity between mouse $T$ and $T r g$ within the T-domain enabled us to detect the Trg protein with the anti-TN $\mathrm{TN}_{1-123}$ antibody that was raised against the amino-terminal part of the mouse $T$-domain (Kispert and Herrmann 1993). The expression of the protein (Fig. 4) essentially shows the same pattern as the RNA. The only difference is that $\operatorname{Trg}$ protein appears slightly later than the RNA-first during cellularization when the ingrowing membranes pass the base of the nuclei. Conse- quently, like Trg RNA at this time, Trg protein is confined to the posterior ring of cells mostly comprising the proctodeal primordium.

\section{Regulation of $\operatorname{Trg}$ expression}

The ring of cells that express Trg during cellularization is contained within the anterior portion of the cap of tllexpressing cells but is largely anterior to the cap of $h k b$ expressing cells (Fig. 5). Therefore, it appears likely that $h k b$ acts as a repressor of $\operatorname{Trg}$ posteriorly and sets its posterior border of expression, whereas tll acts as an activator of $T r g$ expression. The expression pattern of $T r g$ in $h k b$ and $t l l$ mutant embryos suggests this to be the case. In $h k b$ embryos, both Trg RNA (Fig. 3D) and Trg protein (Fig. $6 \mathrm{~B}$ ) are expressed up to the posterior pole of the embryo, whereas expression at the anterior border 


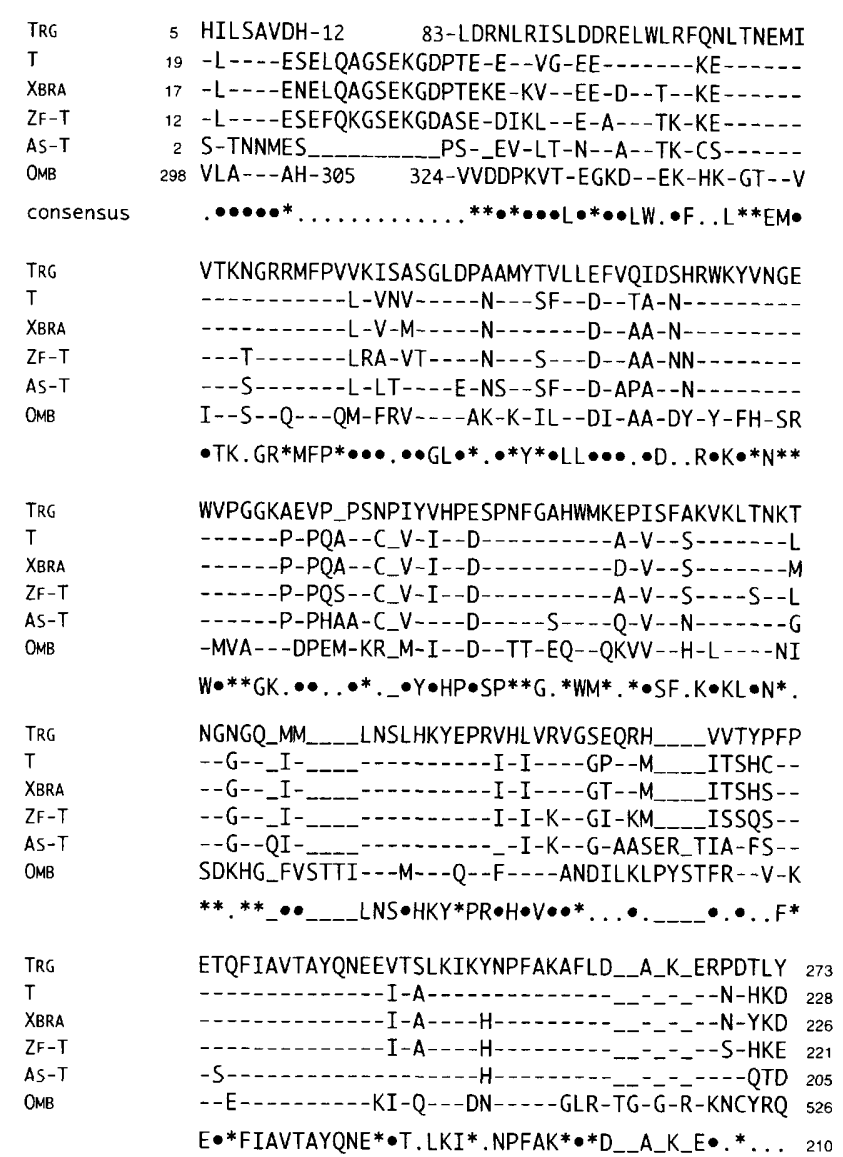

Figure 2. Comparison between the $\mathrm{T}$-domains of the $\mathrm{T}$ proteins from mouse, Xenopus, zebrafish, and ascidian of the Drosophila proteins $\mathrm{Omb}$ and Trg. The conserved regions of Trg, the Xenopus Xbra (Smith et al. 1991), the mouse T (Herrmann et al. 1990), the zebrafish Zf-T (Schulte-Merker et al. 1992), the ascidian As-T (Yasuo and Satoh 1994), and the Drosophila Omb protein (Pflugfelder et al. 1992) are compared. In the consensus sequence only those amino acids identical in all six proteins are shown. Similar amino acids at a given position in all six proteins, or identical or similar amino acids in five proteins including $O \mathrm{mb}$, are represented $(0)$. An asterisk (*) indicates that $\mathrm{Trg}$ and the chordate $\mathrm{T}$ proteins have an identical or similar amino acid at a given position but that the corresponding amino acid in Omb is different. (.) Amino acid positions with less or no similarity. For maximum similarity, gaps (underscore) have been allowed. The following groups of amino acids were considered as similar: $\mathrm{R}$ and $\mathrm{K}_{;} \mathrm{D}$ and $\mathrm{E} ; \mathrm{N}$ and $\mathrm{Q} ; \mathrm{S}$ and $\mathrm{T} ; \mathrm{A}, \mathrm{F}, \mathrm{L}, \mathrm{M}, \mathrm{I}, \mathrm{V}, \mathrm{W}$ and $\mathrm{Y}$.

remains unchanged. In contrast, no $\operatorname{Trg}$ expression is detectable in tll mutant embryos (Fig. 6C).

Some of the functions of $h k b$ and $t l l$ appear to be mediated by fkh (Casanova 1990; Gaul and Weigel 1991). However, the blastoderm expression of Trg is independent of $f k h$ function (Fig. 6D). Also, the maintenance of Trg expression during germ-band extension does not appear to require $f k h$ activity, as $\operatorname{Tr} g$ is still expressed in the developing hindgut and anal pads when these disintegrate in $f k h$ mutant embryos (data not shown).

In the anterior part of the embryo there is also a do- main in which tll, but not $h k b$, is expressed (Fig. 5). If $t 11$ and $h k b$ were the only regulators of $\operatorname{Trg}$ expression, $\operatorname{Tr} g$ should also be expressed in this domain. However, this is not the case, suggesting that, directly or indirectly bicoid $(b c d)$ prevents $t l l$-dependent $T r g$ expression in the anterior part of the embryo. In embryos derived from bcd mutant mothers, the posterior terminal region is duplicated at the anterior pole (Frohnhöfer and Nüsslein-Volhard 1986). This duplication includes the Trg expression in the blastodermal ring of cells and later in the duplicated anterior hindgut (data not shown).

\section{The Trg locus}

By in situ hybridization to polytene chromosomes the $\operatorname{Trg}$ locus was mapped to the region 68DE. This result was confirmed by the examination of $\operatorname{Trg}$ expression in embryos homozygous or transheterozygous for various deficiencies covering the region (Akam et al. 1978). Embryos homozygous for $D f(3 L) v_{\text {vin }}{ }^{2}$ and $D f(3 L)$ vin $^{66}$, but not embryos homozygous for $D f(3 L)$ vin $^{3}$ and $D f(3 L)$ vin $^{4}$, express $\operatorname{Trg}$ (Fig. 7). This places $\operatorname{Trg}$ in the interval (68D6;68E3-4), which was genetically characterized previously and has probably been saturated with lethal mutations (Hoogwerf et al. 1988). Within this interval five complementation groups have been found, one of which corresponds to the cyclin $A(c y c A)$ gene (Lehner et al. 1991). Because $\operatorname{Trg}$ does not correspond to $c y c A$, this probably leaves $\operatorname{Trg}$ as one of the four remaining lethal complementation groups placed in this interval.

\section{Trg function in the development of hindgut and anal pads}

To address the role of $\operatorname{Tr} g$ we examined embryos lacking Trg function. We used embryos transheterozygous for the deficiencies $D f(3 L)$ vin $^{4}$ and $D f(3 L)$ vin $^{6}$ (Fig. 8 ) or homozygous for $D f(3 L) v^{2}{ }^{3}$ (data not shown), as point mutations in $T r g$ are not available at present: The mutations representing the four complementation groups mentioned above have been lost from the stock collections. However, we attribute the defects described below to the lack of $\operatorname{Tr} g$ function, as they correlate strictly with the deletion of the chromosomal region encoding $\operatorname{Tr} g$ and are

Table 1. Similarities between T-domains

\begin{tabular}{lccccc}
\hline & T & Xbra & Zf-T & As-T & Omb \\
\hline Trg & 88 & 88 & 86 & 81 & 66 \\
T & & 96 & 93 & 83 & 69 \\
Xbra & & & 96 & 85 & 69 \\
Zf-T & & & & 86 & 68 \\
As-T & & & & & 62 \\
\hline
\end{tabular}

The percentage of amino acids identical or similar within the T-domains of $\mathrm{Trg}$, of the mouse $\mathrm{T}(\mathrm{T})$, Xenopus $\mathrm{T}$ (Xbra), zebrafish $\mathrm{T}(\mathrm{Zf}-\mathrm{T})$, ascidian $\mathrm{T}(\mathrm{As}-\mathrm{T})$ and the Drosophila Omb protein are given. The glycine-rich region of $\operatorname{Trg}$ (amino acids 15-78) has not been considered in the calculation. Otherwise, the numbers are based on the T-domains as shown in Fig. 2. 

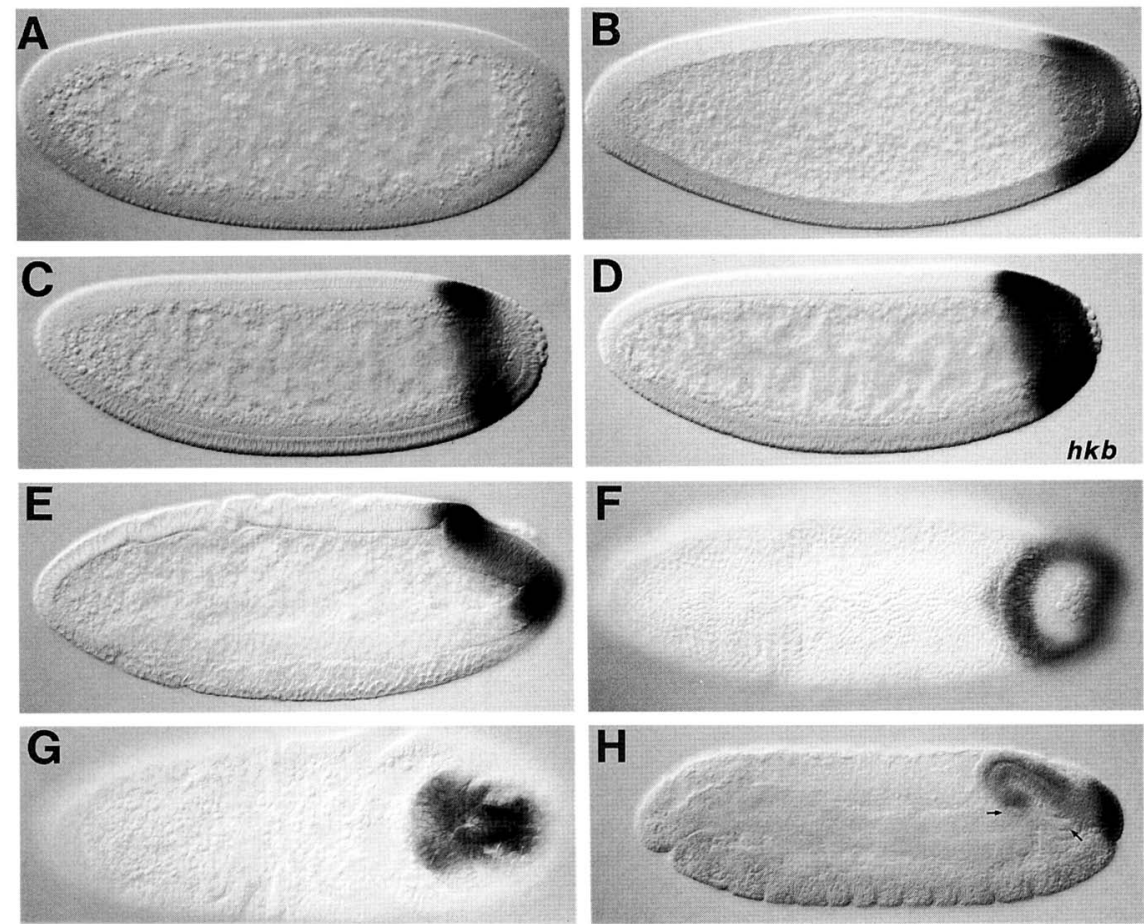

Figure 3. The RNA expression of Trg. $(A)$ Trg RNA is not expressed in the embryo at stage 4, cycle 13. (B) At the onset of cycle 14, transcription commences throughout the posterior terminal region of the embryo. (C) During cellularization the expression is down-regulated in the posterior tip of the embryo and becomes confined to a ring of cells that encompasses the primordium of hindgut and anal pads. (D) Trg RNA expression in a $h k b$ mutant embryo during cellularization. $\operatorname{Tr} g$ is expressed to the posterior tip of the $h k b$ embryo suggesting that in the wild-type embryo $h k b$ sets the posterior border of Trg expression (cf. $C|| E$.$\rangle Early gastrulation. The ventral$ portion of the Trg-expressing ring of cells forms the most posterior part of ventral furrow. The most dorsal part of the ring forms the most anterodorsal aspect of the amnioproctodeal invagination. $(F)$ Same embryo as in $E$ but in dorsal surface view. The ring encircles the posterior midgut primordium (located around and beneath the pole cells). $(G)$ The posterior midgut has invaginated fully. $(H)$ After germ-band retraction Trg expression is confined to the hindgut and anal pads. The Malphigian tubules (arrows) do not express Trg. All embryos are shown in a sagittal optical section and with their anterior to the left (except $F$ and $G$, where dorsal surface views are shown).

not seen in embryos homozygous for the deficiencies $D f(3 L)$ vin $^{2}$ or $D f(3 L)$ vin $^{66}$ nor in embryos lacking only cycA function. Most importantly, the defects can be rescued by a $20-\mathrm{kb}$ transgene carrying the $\operatorname{Trg}$ transcription unit (Fig. 9).

In Trg-deficient embryos the major part of the hindgut is missing after germ-band retraction, as is evident by the absence of hindgut tissue expressing $\beta$-galactosidase, conferred by the enhancer trap insertion A27 (Fig. 8A,B). Early gastrulation, including the invagination of the amnioproctodeum, proceeds normally in the Trg-deficient embryos (data not shown). It is not until the germ band has extended almost fully that the proctodeum begins to develop aberrantly and, for example, does not express the proper stripe of En protein (Fig. 8C,D). Normally, En protein is found along the major part of the proctodeum in a stripe running in an anterior-posterior extension (Fig. 8C). In addition, the anal pads are not formed in Trgdeficient embryos. Zygotic cad, which is known to be required for the proper differentiation of the anal pads (Macdonald and Struhl 1986), is not expressed in their primordium (Fig. 8F). Only a few cells at the posterior tip
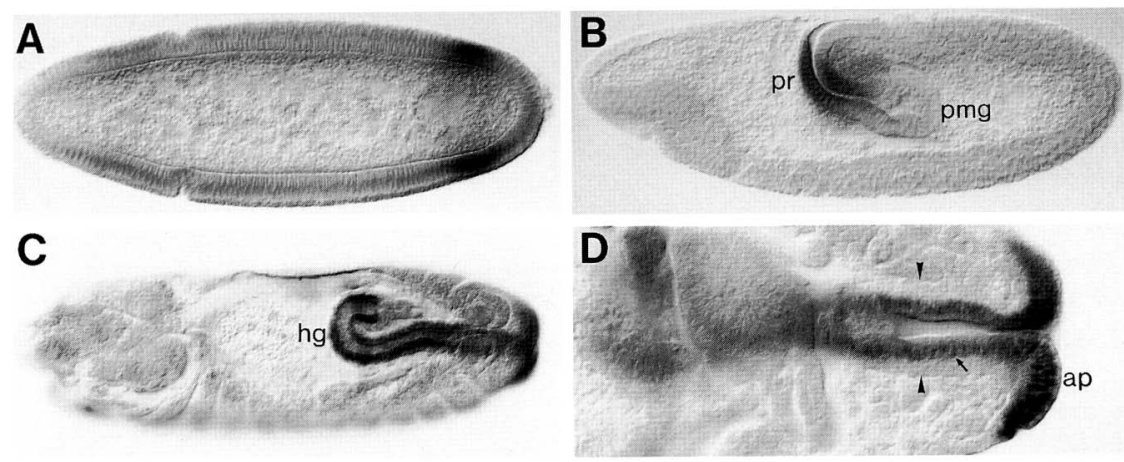

Figure 4. The expression of Trg protein. Trg protein is visualized with the anti$\mathrm{TN}_{1-123}$ antibody that is directed against the amino-terminal half of the mouse T-domain. (A) Late blastoderm, onset of ventral furrow formation. Trg protein is detected in a region encompassing the primordia of hindgut and anal pads and of the most posterior part of the mesoderm. $|B|$ Germ band extension. Trg protein is confined to the proctodeum (pr). (C) Fully retracted germ band. Trg protein is found in the hindgut $(\mathrm{hg})$ and the anal pads but not in the Malpighian tubules. (D) Enlarge ment of the posterior part of the embryo in $C$, showing localization of Trg protein in the apically located nuclei (arrow) of the hindgut epithelium. The arrowheads mark the basal side of the epithelium. The level of $\operatorname{Trg}$ protein expression increases in the course of embryogenesis allowing for a better subcellular localization of the protein in later $|C|$ than in earlier $(A, B)$ stages. $\{A, C, D \mid$ Dorsal view, optical horizontal section; $(B)$ lateral view, optical sagittal section. (ap) Anal pads; (hg) hindgut; (pmg) posterior midgut; (pr) proctodeum. 


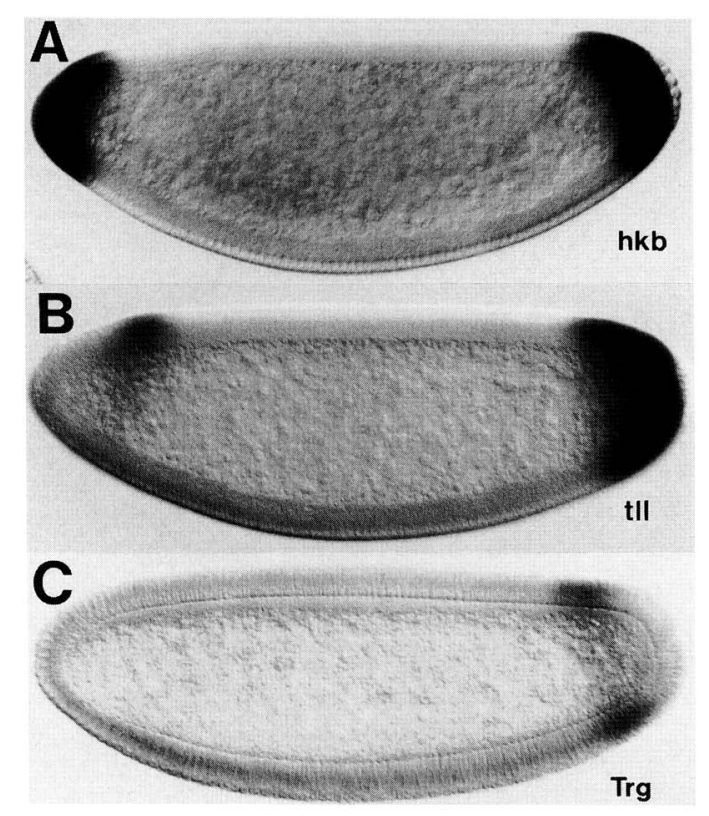

Figure 5. Spatial comparison of the expression of $\operatorname{Trg}$ and the terminal gap genes $h k b$ and $t l l .|A| h k b$ RNA expression at the onset of cellularization. $(B)$ tll RNA expression at the onset of cellularization. $(C)$ Trg protein at almost complete cellularization. Trg is expressed in that part of the posterior terminal region where $t l l$, but not $h k b$, is expressed. All embryos are shown in an optical sagittal section.

of the germ band express Cad protein and presumably constitute the precursors of more anteriorly located epidermal structures in which Cad is also expressed (Fig. $8 \mathrm{E}$ ). Additionally, during germ-band retraction evenskipped is also expressed in the anal pads of wild-type embryos, but no corresponding expression is detectable when Trg function is lacking (data not shown).

The posterior end of the midgut is connected to the outside by a short tube in Trg-deficient embryos (Fig. $8 \mathrm{~B}, \mathrm{H})$. This tube does not appear to be a rudimentary hindgut but seems to consist of epidermis that normally would be located at the outside of the embryo. This displacement of tissue in the Trg-deficient embryos is best seen in embryos stained for Wg protein. Normally $\mathrm{Wg}$ protein brackets the hindgut perfectly, as it is found at the base of the Malpighian tubules and in the anal pads (Fig. 8G). In the Trg-deficient embryos these two regions of $\mathrm{Wg}$ expression are separated by only a few cells (Fig. $8 \mathrm{H})$. The part of the tube behind the posterior, larger $\mathrm{Wg}$ expression domain appears to be formed by posterior epidermis that has moved into the embryo. This interpretation is based on the observation that this part of the tube expresses $A b d o m i n a l-B$ ( $A b d-B$; data not shown), which in wild-type embryos is found in the posterior segmented regions of the embryo adjacent to Trg (Celniker et al. 1989; data not shown). In conclusion, we suggest that Trg plays a crucial role in the development of the hindgut and the anal pads. The lack of Trg function appears to exert a gap gene-like phenotype that specifically affects these two structures.

\section{Genes homologous to Trg exist in short-germ insects}

Because the antibody directed against the T-domain of the mouse $\mathrm{T}$ protein cross-reacts with the product of the Drosophila Trg we expected that it would also bind to T-related proteins in other insects. In both Locusta migratoria and Tribolium castaneum we detected apparently nuclear gene products with the antibody (Fig. 10). Because these are expressed exclusively in the posterior tip of the embryo (the putative primordium of the proctodeum/ and in the developing hindgut, as is the case in Drosophila, we assume that they are homologous to Drosophila Trg.

A detailed comparison of the expression patterns in the different insects might allow us to begin to assess the evolution of $\operatorname{Trg}$ gene function. Both Locusta and Tribolium are short-germ insects that undergo a very different segmentation process compared with the long-germ insect Drosophila (for review, see Anderson 1972a,b). The segmental primordia of long-germ insects are deter-
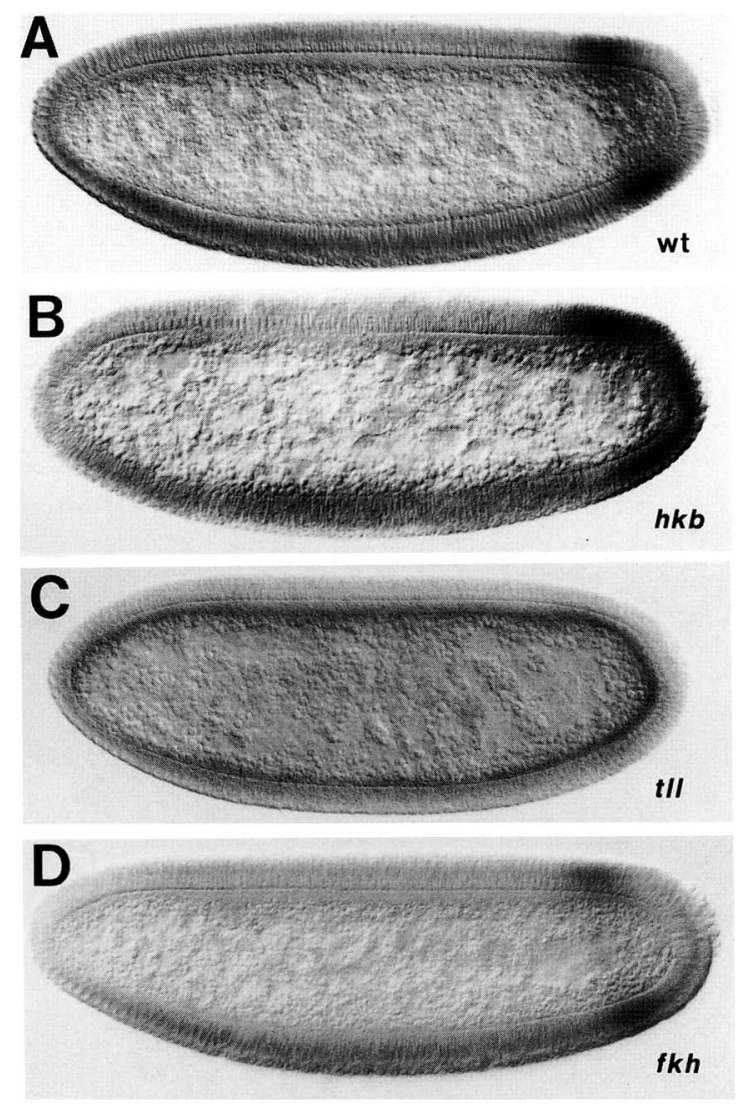

Figure 6. $t l l$ and $h k b$ regulate $\operatorname{Trg}$ expression. Trg protein expression at blastoderm stage is shown for wild-type $(A), h k b(B)$, $t 11|C\rangle$, and $f k h(D)$ embryos. $(A)$ In the wild-type embryo Trg is expressed in a circumferential ring of cells in the posterior terminal region. $(B)$ The posterior boundary of the expression domain is set by $h k b$, as Trg expression is extended to the posterior pole in $h k b$ mutant embryos. $(C) t l l$ acts as an activator of Trg expression, as no Trg is detectable in tll mutant embryos. (D) The early expression of $\mathrm{Trg}$ does not depend on $f k h$ function. 


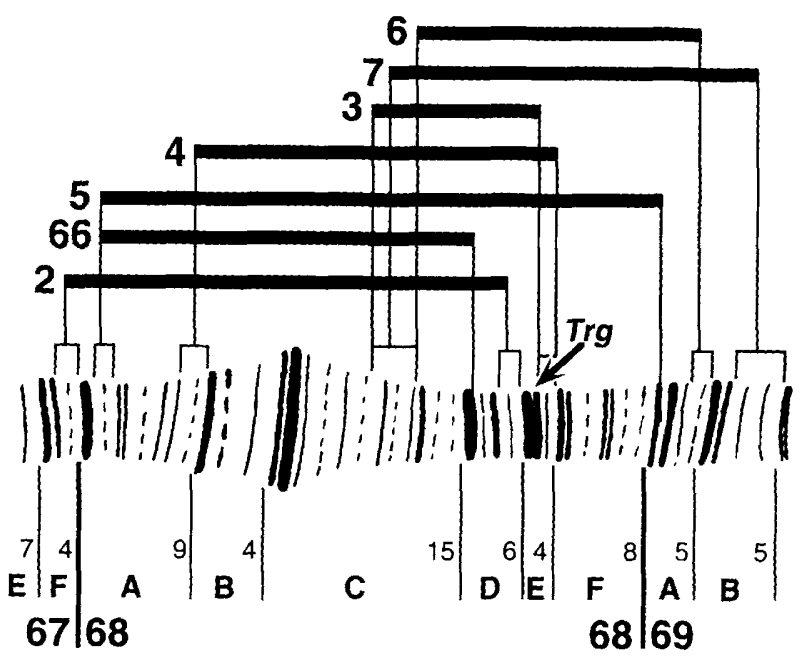

Figure 7. The chromosomal localization of Trg. The Trg locus is uncovered by the deficiencies $D f(3 L) v_{\text {vin }}^{3}, D f(3 L) v^{2}{ }^{4}$, $D f(3 L) v_{v i n}^{5}, D f(3 L) v i n^{6}$, and $D f(3 L) v_{\text {vin }}^{7}$ but excluded from the deficiencies $D f(3 L) v_{v i n^{2}}$ and $D f(3 L)$ vin $^{66}$. This places Trg in the region between $68 \mathrm{D} 6$ and 68E3-4. The chromosomal breakpoints of the vin deficiencies are taken from Akam et al. (1978).

mined essentially simultaneously over the entire length of the body at the same time as the terminal primordia during the early blastoderm stage. In contrast, both Locusta and Tribolium first form a head germ and then gradually add thoracic and abdominal segment primordia. It is not known when the terminal primordia are determined.

Locusta migratoria In Locusta no Trg expression is detectable at $15 \%$ of development when the head germ has formed and only the head lobes and tail-like growth zone are visible (data not shown). Trg is first expressed at $\sim 20 \%$ of development, at the very posterior tip of the embryo, when a morphological border between the thoracic and the abdominal segment primordia is visible (Fig. 10A). At this time, the first abdominal segment becomes distinguishable in the closely related species Schistocerca americana (Patel et al. 1989b). This expression of Trg suggests that the determination of the posterior terminus occurs before most of the posterior abdominal segment primordia have been laid down. Slightly later, at $\sim 23 \%$ of development, when there is still no morphological sign of segmentation in the abdomen, but molecular methods allow the identification of three $a b$ dominal segment primordia (Patel et al. 1989b), Trg expression has increased in level and is found in the entire posterior tip of the embryo within the ectoderm (Fig. 10B,C). Trg continues to be expressed in these terminal cells (Fig. 10D), which at $\sim 29 \%$ of development begin to invaginate perpendicular to the body axis to form the proctodeum (Fig. 10E,F). Within the cells of the proctodeal invagination the expression of Trg gradually declines toward the inner, more dorsally located part (Fig. 10F|. Later, when the proctodeum has extended and is positioned parallel to the body axis, Trg expression is still present in the developing hindgut (data not shown). However, the inner end of the proctodeal tube does not express the Trg gene any longer. This part might constitute the primordium of the posterior midgut of the Locusta embryo. We did not follow the expression of $\operatorname{Trg}$ later than $40 \%$ development.

Tribolium The expression of Trg in Tribolium embryos essentially follows the same temporal and spatial pattern as in Locusta. $\operatorname{Trg}$ is expressed at the posterior tip of the developing germ band before all of the abdominal segment primordia have been laid down (Fig. 10G). However, the earliest expression that we were able to detect occurs later, relative to the segmentation process, than observed in Locusta. The fifth abdominal segment is already morphologically distinguishable (Fig. 10G). The cells of the posterior tip later form the proctodeal invagination $(60 \mathrm{hr}$ of development; Fig. $10 \mathrm{H}, \mathrm{I})$ after the entire germ band has formed and all segmental primordia are morphologically distinguishable. As in Locusta, the protein expression declines toward the inner part of the proctodeum (Fig. 10I), which might constitute the primordium of the posterior midgut. After retraction of the germ band, $\mathrm{Trg}$ is found in the hindgut and the anus and is not expressed in any other part of the body including the tissue developing from the closed end of the proctodeum (Fig. 10K).

\section{Discussion}

\section{A family of genes defined by the T-domain}

Trg exhibits a very high similarity $\{88 \%$ ) over a stretch of 200 amino acids (the $T$-domain) to the $T$ genes of chordates \{Fig. 2\}. This domain has been shown to be required and sufficient for specific DNA binding and defines a novel family of DNA-binding proteins that possibly function as transcription factors (Kispert and Herrmann 1993). There is one other Drosophila gene containing a T-domain, omb (Pflugfelder et al. 1992), which is, however, less closely related to the $T$ genes of chordates than $\mathrm{Trg}$. omb is distinguished by a few features, like two insertions within the T-domain, from all of the other genes of the family. In addition, the antibody directed against the 123 amino-terminal amino acids of the mouse $\mathrm{T}$ protein does not cross-react with $\mathrm{Omb}$ /data not shown; for embryonic omb expression, see Poeck et al. 1993), whereas this antibody does recognize the products of vertebrate $T$ genes and of the insect $\operatorname{Trg}$ (Kispert and Herrmann, 1993; Figs. 4 and 10; data not shown). Omb probably constitutes a member of a particular class of $T$-domain proteins. We predict that in vertebrates omblike genes also exist, just as $\operatorname{Tr} g$ exist in insects, and we speculate that these two are not the only classes of the $\mathrm{T}$-domain gene family.

\section{The regulation of $\operatorname{Trg}$ expression}

The Trg expression in mutant embryos suggests that during late blastoderm stage, Trg is activated by tll and repressed by $h k b$ (Fig. 6). Because tll expression appears to 
Kispert et al.

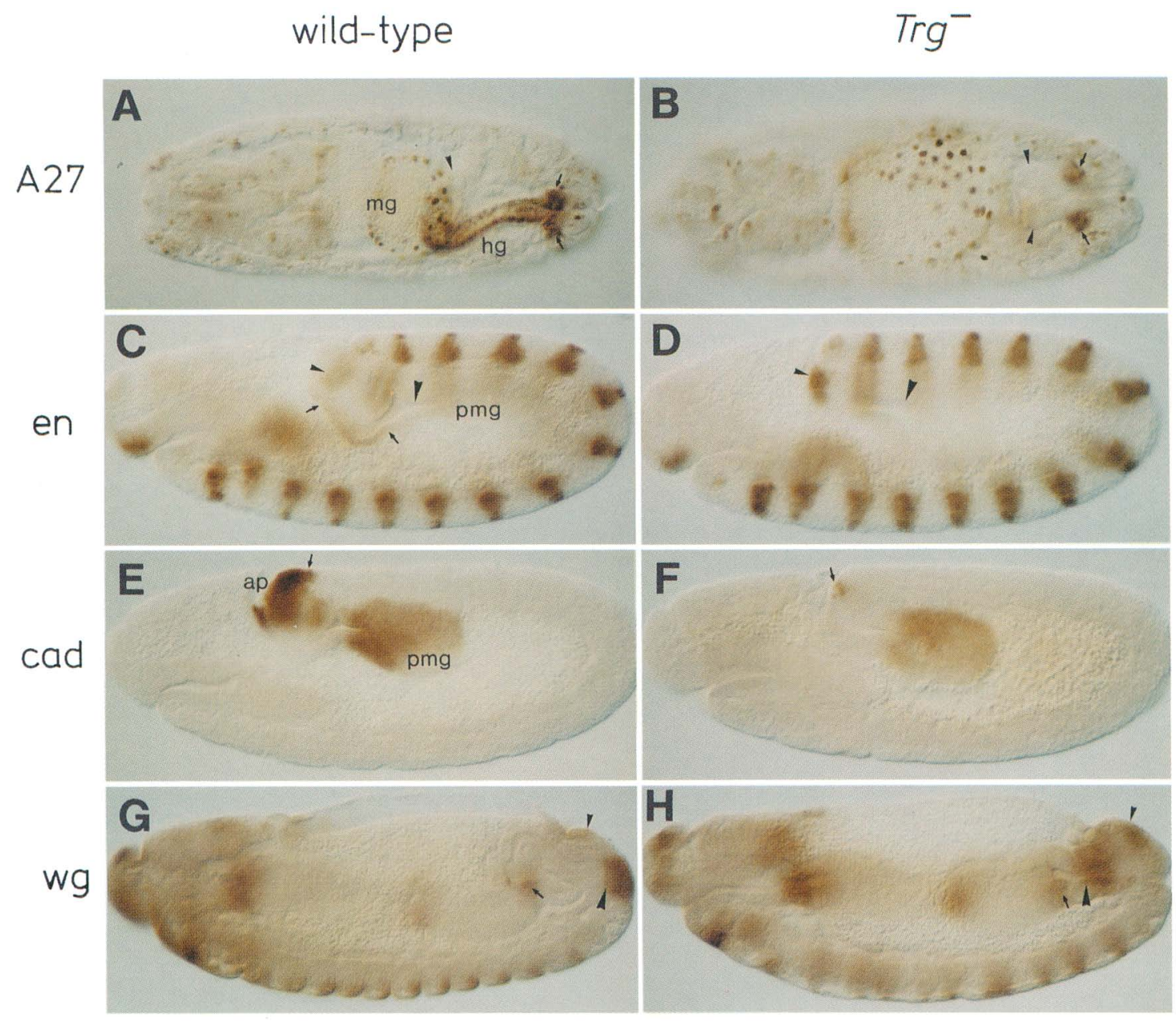

Figure 8. The development of hindgut and anal pads requires $\operatorname{Tr} g$ function. $\beta$-galactosidase expression conferred by the enhancer trap insertion $\mathrm{A} 27(A, B)$ En protein expression $(C, D)$, Cad protein expression $(E, F)$, and $\mathrm{Wg}$ protein expression $(G, H)$ is shown for wild-type embryos $(A, C, E, G)$ and in embryos carrying a small synthetic deficiency formed by the overlap of the deficiencies $D f(3 L) v i n^{4}$ and $D f(3 L)$ vin $^{6}(B, D, F, H)$. $(A)$ The enhancer trap insertion A27 normally confers $\beta$-galactosidase expression in the hindgut (hg), in a particular region of the midgut $(\mathrm{mg}$ ), and in a part of the posterior spiracles (arrows) at stage 16 (dorsal view). The arrowhead marks the base of the Malpighian tubules. $(B)$ In a Trg-deficient embryo of about the same age as that in $A$, the $\beta$-galactosidase-expressing loop of the hindgut is missing. The arrowheads mark the developing Malpighian tubules. $(C)$ In the wild-type embryo, a stripe of En protein is expressed within the ventrally located part of the proctodeum (between arrows) during germ-band extension. The small arrowhead marks the epidermal En expression of the rudimentary ninth abdominal segment $\{a 9\}$, and the larger arrowhead indicates the transition between proctodeum and posterior midgut. $(D)$ In a Trg-deficient embryo the part of the proctodeum containing the En stripe is missing. The En expression in a9 (smaller arrowhead) appears to be stronger than normal, as it crosses the midline of the mutant embryo, i.e., the focal plane of the optical sagittal section shown. In the wild-type embryo, the expression is confined to a lateral stripe in the hemisegment and excludes the middle part of the embryo. $(E)$ Cad protein is expressed in the anal pads (ap), a few neighboring cells of the epidermis (arrow) and the developing posterior midgut (pmg) during germ-band extension. (F) In Trg-deficient embryos the anal pads and the corresponding Cad expression are absent, but the development of the posterior midgut is undisturbed. (G) At stage 13 (after germ-band retraction) Wg protein is expressed within the posterior terminal region in parts of the anal pads (larger arrowhead) and at the base of the Malpighian tubules at the junction between hindgut and posterior midgut (arrow). The smaller arrowhead indicates expression in the terminal epidermis. $(H)$ The $\mathrm{Wg}$ expression in Trg-deficient embryos indicates that the major part of the hindgut between the base of the Malpighian tubules (arrow) and the cells corresponding to the anal pads (larger arrowhead) is missing.

extend beyond the anterior border of Trg expression /data not shown; cf. Pignoni et al. 1990) it is reasonable to assume that a particular threshold of tll activity is required for $\operatorname{Tr} g$ expression. In the anterior part of the embryo, either tll activity does not surpass this threshold (because the modulating effect of $b c d$ on the $t 11$ expres- sion) or $b c d$ itself prevents the activation of $\operatorname{Tr} g$ by $t 11$ (data not shown). We assume that both $t l l$ and $h k b$ are direct transcriptional regulators of $\operatorname{Trg}$ at the blastoderm stage. Other genes active in the posterior terminal region like $f k h$, which itself depends on $h k b$ or $t l l$, are not required for the early expression of Trg (Fig. 6D). Most 

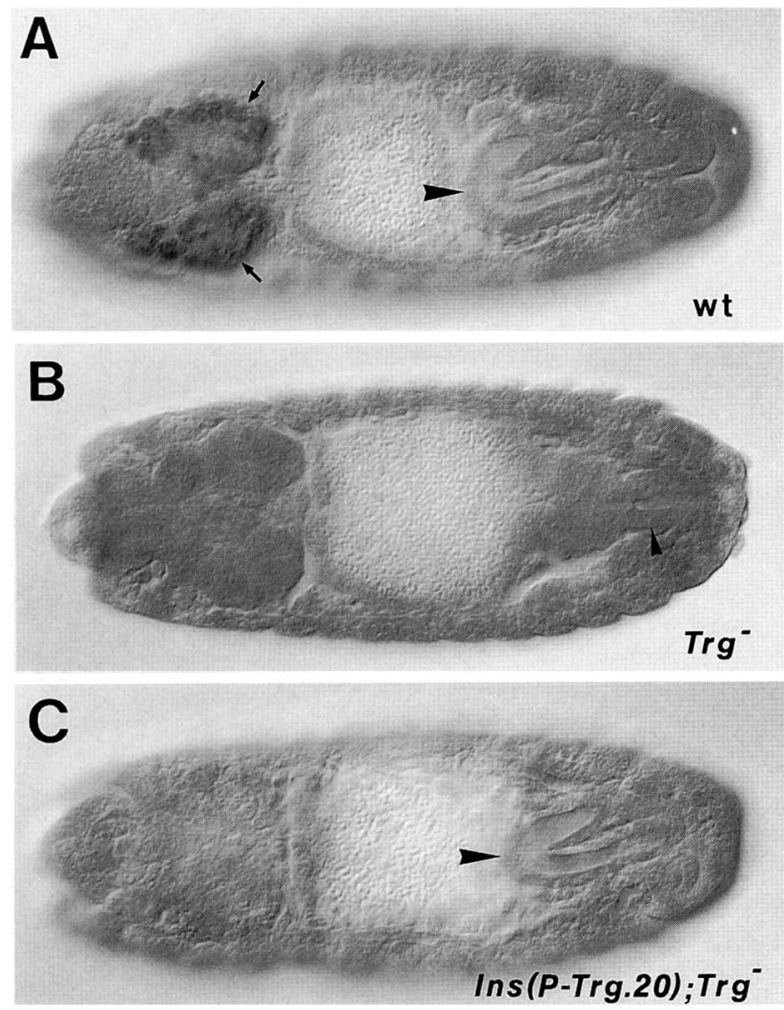

Figure 9. A $20-\mathrm{kb}$ transgene provides $\operatorname{Trg}$ function. Wild-type embryos $(A)$, embryos transheterozygous for the deficiencies $D f(3 L) v_{\text {vin }}^{4}$ and $D f(3 L) v^{\prime} n^{6}|B|$, or embryos transheterozygous for the deficiencies $D f(3 L)$ vin ${ }^{4}$ and $D f(3 L)$ vin $^{6}$ and heterozygous for the transgene P-Trg20A $|C|$ were immunostained for the Cyclin A protein. $|A|$ In the wild-type embryo only the nervous system (arrows: brain) expresses Cyclin A at stage 14 (large arrowhead: hindgut loop). $(B)$ In the Trg-deficient embryos there is no Cyclin A protein detectable and the hindgut is absent (small arrowhead). $(C)$ Trg-deficient embryos $\left(D f(3 L)\right.$ vin $\left.^{4} / D f(3 L) v_{\text {vin }}^{6}\right)$ that are heterozygous for the $\operatorname{Trg}$ transgene P-Trg20A also show no Cyclin A expression, but the development of the hindgut (large arrowhead) and of the anal pads is rescued.

likely, $\operatorname{Tr} g$ and $f k h$ act in parallel, since $f k h$ expression is unchanged in Trg-deficient embryos at the blastoderm stage or early gastrulation (data not shown).

When the proctodeum has fully invaginated, the gene $s r p$ takes over the role of $h k b$ in repressing Trg in the primordium of the posterior midgut (Reuter 1994). A further gene might exist that is expressed in the mesodermal germ layer and turns off $\operatorname{Trg}$ in those cells that invaginate at the posterior tip of the ventral furrow. However, $\operatorname{Trg}$ could also be positively regulated, and there might be a particular gene that is required for the maintenance of Trg expression in hindgut and anal pads. There is no indication that $f k h$ regulates late $T r g$ expression, since in $\mathrm{fkh}$ mutant embryos Trg expression decays concomitantly with the cellular integrity of the proctodeum. It is conceivable that Trg itself is required for the maintenance of its own expression and possesses autoregulatory properties. A similar function has been sug- gested for the maintenance of $T$ gene expression in the notochord (Herrmann 1991).

\section{The function of $\operatorname{Trg}$ in Drosophila}

The loss of $\operatorname{Trg}$ function causes a gap gene-like phenotype in the Drosophila embryo. Based on morphological criteria and the expression pattern of tissue-specific markers, we conclude that the anal pads and the major part of the hindgut are missing in Trg-deficient embryos (Fig. 8). This phenotype is specifically associated with the deletion of the region $(68 \mathrm{D} 6 ; 68 \mathrm{E} 3-4)$ and can be rescued by a $\operatorname{Trg}$ transgene.

Among the genes whose expression is affected in Trgdeficient embryos is cad, which may normally mediate some of the functions of $\operatorname{Tr}$, as cad is itself required for the proper differentiation of the anal pads (Macdonald and Struhl 1986). The Malpighian tubules and their base, which like the hindgut are derived from the proctodeum, develop essentially normal in Trg-deficient embryos. Thus, only those structures that normally express $\operatorname{Trg}$ are affected.

$\operatorname{Trg}$ is not only expressed early in the primordia of hindgut and anal pads, but also later in the definitive organs, a pattern that is unusual and reminiscent of homeotic gene expression. It is conceivable that $T r g$ acts as a selector gene and positionally specifies these body parts like a homeotic gene, although its lack-of-function phenotype is that of a gap gene. Such behavior is observed for homeotic genes acting in the Drosophila head, like Deformed $(D f d)$, the homeotic character of which is revealed only upon ectopic expression. In contrast, the lack of $D f d$ function causes a gap in the body plan and not a homeotic transformation (Kuziora and McGinnis 1988).

The phenotypic analysis of $s r p$ mutant embryos led to the conclusion that a selector gene must exist that is responsible for hindgut-specific morphogenesis and differentiation (Reuter 1994). srp embryos develop an additional hindgut in place of the posterior midgut. This phenotype can be regarded as a homeotic transformation when posterior midgut and hindgut are considered as serial homologs. The transformation in srp mutant embryos is accompanied by an expansion of Trg expression into the posterior midgut primordium at stage 8 . This is consistent with the possibility that Trg might be the hindgut selector gene. However, it remains to be determined whether or not $\operatorname{Trg}$ alone has the capacity to direct hindgut development when expressed ectopically in the midgut primordia.

\section{Trg function in short-germ insects}

The proteins detected in Locusta and Tribolium by the anti-TN $\mathrm{TN}_{1-123}$ antibody are most likely encoded by genes homologous to Trg in Drosophila. First, the cross-reactivity of the antibody suggests a structural similarity to the vertebrate $T$ genes as we have shown for $\operatorname{Trg}$ in Drosophila. Second, both in Locusta and Tribolium, Trg is expressed exclusively, as in Drosophila, in the poste- 

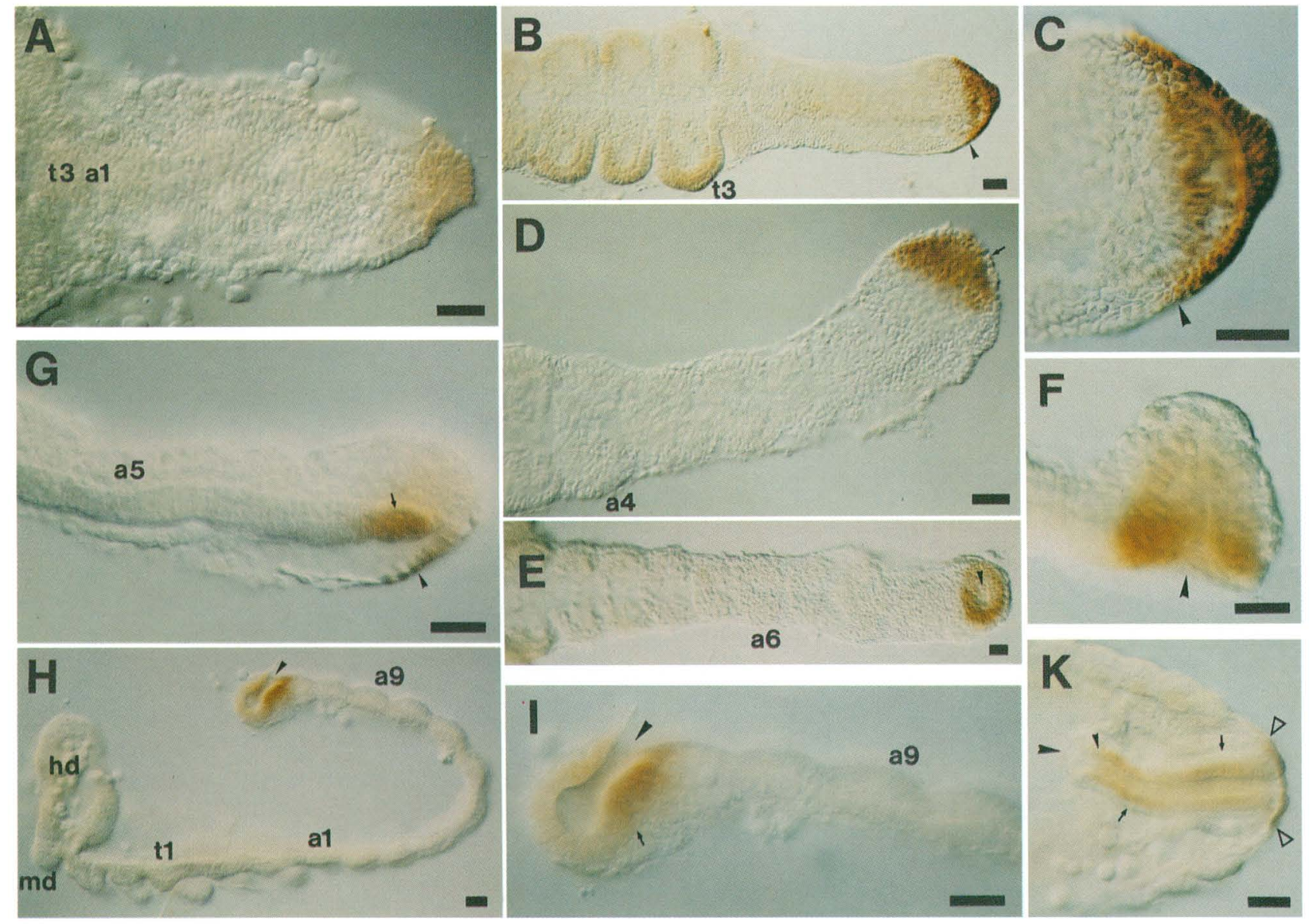

Figure 10. Expression of Trg homologs in Locusta and Tribolium embryos. The protein products of Trg in $L$. migratoria $(A-F\rangle$ and in $T$. castaneum $(G-K)$ have been detected with the anti-TN $\mathrm{TN}_{1-123}$ antibody. $(A)$ Approximately $21 \%$ development. The posterior tip of the embryo expresses Trg. The approximate border between thoracic and abdominal primordia $(\mathrm{t} 3$ al $)$ has been determined by morphological criteria. $(B)$ Approximately $23 \%$ development. Trg expression is confined to the posterior tip. The arrowhead marks the sharp border of expression ( $\mathrm{t} 3$ : primordium of the third thoracic segment). $(C)$ Enlargement of the tail tip of the embryo shown in $B$. The expression is predominantly ectodermal. $\{D \mid$ Approximately $26 \%$ development. Segmentation can be distinguished morphologically up to about abdominal segment 7 . Cells not expressing Trg (arrow) form a layer apparently posterior to the Trg expression domain and are probably serosa cells that connect to the posterior tip of the germ band (a4: primordium of the fourth abdominal segment). (E) Approximately $29 \%$ development. The proctodeum that expresses Trg has started to invaginate (arrowhead). $(F)$ Enlargement of the proctodeum of the embryo shown in $E$. The expression of Trg declines in strength toward the dorsal, inner side of the proctodeum. The arrowhead indicates the proctodeal opening. (G) Posterior region of a Tribolium embryo during anatrepsis [ $\sim 40 \mathrm{hr}$ of development; (a5) primordium of the fifth abdominal segment]. Trg is expressed at the posterior tip of the germ band (arrow) and the serosal membrane (arrowhead). $(H)$ Embryo after completion of the segmentation process ( $\sim 60 \mathrm{hr}$ of development). The arrowhead indicates the opening of the proctodeum which expresses Trg. (hd) Head; (md) mandibular segment; (tl) first thoracic segment; (al and a9) first and ninth abdominal segment. $(I)$ Enlargement of the proctodeum of the embryo shown in $H$. The expression of Trg declines in strength towards the dorsal, inner side of the proctodeum. The arrow indicates the border between proctodeum and adjacent mesoderm. $(K)$ Enlargement of the posterior region of an embryo after full retraction of the germ band $(\sim 100 \mathrm{hr}$ of development $)$. Trg is expressed around the anus (between open arrowheads). It is confined to the ectodermal epithelium of the hindgut (small solid arrowhead), whereas the mesoderm surrounding the hindgut (arrows) is devoid of the protein. The primordium of the midgut that is contiguous with the hindgut (large solid arrowhead) also does not express Trg. Scale bars correspond to $25 \mu \mathrm{m}$.

rior terminal region, where the primordium of the proctodeum is presumably located, in the proctodeum itself, and finally in the proctodeal derivatives hindgut and anus. These findings suggest that $\operatorname{Tr} g$ has a homologous and phylogenetically well-conserved function in the specification of the proctodeum and its derivatives in insects. The proctodeum in "lower" (grasshopper) and in "higher" (beetles and flies) insects appears to be determined by similar molecular mechanisms.

Several aspects of Trg expression in Locusta and Tribolium are of further interest. Trg is not detectable during blastoderm stage. This might be attributable to a lower affinity of the antibody for these proteins than for Trg in Drosophila. It is, however, more likely that the 
determination of the posterior terminus in the two short-germ insects occurs comparatively later than in Drosophila and that this is reflected in the later onset of Trg expression. In short-germ insects the thoracic and abdominal segments are determined and formed sequentially in an anterior to posterior order. Interestingly, in both Locusta and Tribolium, Trg expression appears at the posterior tip of the germ band well before the posterior abdominal segments have formed. This suggests that the proctodeal primordium is determined significantly earlier than the primordia of these abdominal segments.

\section{Is $\operatorname{Trg}$ a homolog of the $\mathrm{T}$ genes?}

Within the T-domain, there is a very high degree of similarity between Drosophila Trg and the $T$ genes of vertebrates. This implies a close phylogenetic relationship between the genes. Is there also a phylogenetic relationship between the developmental processes that these genes regulate? In higher chordates (vertebrates) $T$ is expressed both in the notochord and in the area from which mesendoderm is generated, that is, in the primitive streak (mouse, chick), germ ring (fish), or marginal zone (frog) and later, during axis elongation, in the tail bud. These two domains of expression reflect the twofold function of the $T$ gene during vertebrate development. $T$ is required both for the differentiation of the notochord and for the formation of mesendoderm during posterior axis elongation (for review, see Beddington et al. 1992). The phylogenetically older aspect of $T$ function most likely reflects its role in notochord development, as the $T$ homolog of a lower chordate (ascidian) is expressed exclusively in the cells of the presumptive and definitive notochord (Yasuo and Satoh 1994). The expression of Trg in the proctodeum of insects is certainly not related to the expression of the $T$ genes in the mesendoderm generation zone of vertebrates. The part of the insect embryo that might be considered to be a structure similar to the primitive streak, or the germ ring, is the ventral furrow or gastral groove, and Trg is not expressed there / with the exception of the posterior tip of the furrow). Thus, the question remains whether there is a phylogenetic relationship between the function of $T$ genes in the vertebrate notochord and the insect proctodeum. Did these structures originate from a common precursor? It has been hypothesized that the notochord evolved from the stomochord of hemichordates, a structure that evaginates from the anterior part of the gut (for further discussion, see Siewing 1969). Phylogenetically, the notochord would then be derived from the gut. Connecting this notion to the $T$-gene function leads to the speculation that $T$ specified a particular part of the gut early in evolution. In the branch leading to the arthropods $T$ then became concerned with the specification of the proctodeum, whereas in parallel in the branch leading to the chordates, $T$ became concerned with the specification of a gut derivative, first the stomochord and then the notochord.

The current assignment of notochord and insect hindgut to different germ layers, mesoderm and ectoderm, respectively, is somewhat arbitrary in both cases and is not an argument against their possible common origin. Often the notochord and definitive endoderm are formed from the same progenitor, the head process in mouse, for example (Poelmann 1981), or certain blastomeres in ascidian (Ortolani 1957) that might imply a closer relationship of notochord to endoderm than to mesoderm. Also the assignment of the insect proctodeum to ectoderm and not to endoderm is not based on its (interior) position within the embryo after the gastrulation movements, but on the epithelial properties that the late organ shares with the epidermis (for further discussion, see Skaer 1993). At this point, of course, we can only raise the question of whether there is a phylogenetic relationship between notochord of chordates and proctodeum of arthropods. In this context it would be useful to search for Brachyury class T-domain genes in species that phylogenetically link chordates and arthropods and to investigate the expression pattern and function of such genes during development.

\section{Materials and methods}

Isolation of $\operatorname{Trg} C D N A s$ and sequence analysis

A 687-bp fragment ( $N c O I-E c o R I$ ) encompassing the first 229 codons of the open reading frame of the mouse $T$ gene was isolated from the plasmid pBP4.T(1-229) (Kispert and Herrmann 1993), labeled with $\left[^{32} \mathrm{P}\right] \mathrm{dCTP}$ by random priming and used as a hybridization probe to screen a plasmid cDNA library prepared from 8- to 12-hr Drosophila embryos (Brown and Kafatos 1988). A strongly hybridizing clone (Trg1, 2.6-kb HindIIIEcoRI insert) was isolated under reduced stringency conditions, that is, at $50^{\circ} \mathrm{C}$ in Church buffer (Church and Gilbert 1984). By screening the same filters with a $1.6-\mathrm{kb}$ Sacl fragment of $\operatorname{Trg} 1$ under high stringency conditions $\left(68^{\circ} \mathrm{C}\right.$ in Church buffer $), 10$ additional Trg clones were isolated of which 3 had inserts identical to $\operatorname{Trg} 1$, whereas the others $\{\operatorname{Trg} 2\rangle$ contained a $1.8-\mathrm{kb}$ HindIII-EcoRI insert comprising the $3^{\prime}$ part of the $\operatorname{Trgl}$ insert.

Both strands of Trg1 and the ends of Trg2 were sequenced using the dideoxy method of Sanger (Sanger et al. 1977) with a T7 sequencing kit (Pharmacia, Sweden). Sequence analysis was performed on a Macintosh personal computer using the "MacMolly Tetra" program (Softgene, Germany).

\section{In situ hybridization to polytene chromosomes}

The 3-kb EcoRI insert from the Trgl cDNA clone was labeled with biotinylated dUTP (Bio-16-dUTP, Boehringer Mannheim, Germany) by random priming. Salivary gland chromosome spreads were prepared from Oregon- $R$ third-instar larvae using standard techniques (Langer-Safer et al. 1982). The probe was hybridized to the acetylated and alkali-denatured chromosomes in $0.6 \mathrm{M} \mathrm{NaCl}, 50 \mathrm{~mm} \mathrm{NaPO}_{4}$ (pH 7.0), $5 \mathrm{~mm} \mathrm{MgCl}_{2}$, and $5 \%$ dextran sulfate in Denhardt's solution. The chromosome preparations were washed, and the probe detected as described by Engels et al. (1986) using the streptavidin/biotinylated alkaline phosphatase DNA detection system (BRL, USA). The chromosomes were viewed without counterstaining with a Zeiss Photomicroscope III equipped with phase-contrast optics.

Germ-line transformation and genetic analysis

The bacteriophage P1 clone 2-73 containing genomic DNA from the chromosomal region $68 \mathrm{E} 2,3$ was kindly provided by 
Daniel Hartl (Smoller et al. 1991). Using the Trgl cDNA as a probe, we identified a $20-\mathrm{kb} K p n I$ fragment of the genomic insert that contains exclusively the 8-kb transcription unit of Trg together with $9 \mathrm{~kb}$ of $5^{\prime}$-flanking and $3 \mathrm{~kb}$ of $3^{\prime}$-flanking DNA. This fragment was subcloned into KpnI-digested pCaSpeR4 (Pirrotta 1988). The recombinant clone and the helper plasmid $\mathrm{p} \pi 25.7 \mathrm{wc}$ (Karess and Rubin 1984) were injected into $w^{1118} \mathrm{em}$ bryos as described by Spradling (1986). Two independently transformed fly lines were obtained from the Fl generation, one of which (P-Trg20A) carried the transgene on the second chromosome, the other (P-Tr20B) on the third chromosome.

To test the capacity of the transgene to rescue the hindgut phenotype of the Trg-deficient embryos we crossed the transgene on the second chromosome into the background of $D f(3 L)$ vin $^{6}$ and backcrossed with $D f(3 L)$ vin $^{4}$ females. We examined the embryonic progeny that did not express Cyclin A and, therefore, were transheterozygous for the deficiencies $D f(3 L)$ vin $^{6}$ and $D f(3 L)$ vin ${ }^{4}$. About $50 \%$ of these embryos develop normal hindgut and anal pads. Therefore, we conclude that a single copy of the Trg transgene rescues the hindgut and anal pad phenotype of Trg-deficient embryos. Similar results were obtained with the Trg transgene on the third chromosome, which was recombined onto a $D f(3 L)$ vin $^{6}$ chromosome and tested in trans to $D f(3 L) v_{v i n}^{4}$.

\section{Fly stocks}

$b c d^{E 1}$ is a small deletion of the bcd locus (Berleth et al. 1988). $h k b^{A}$ is commonly used as $h k b$ deficiency (Weigel et al. 1990). $t l^{g}$ is a small deficiency of the tll locus, used here as $t 11$ null allele (Strecker et al. 1988). $f k h^{X T 6}$ is a small deficiency of the $f k h$ locus (Weigel et al. 1989b). A27 is an enhancer trap insertion on the second chromosome (O'Kane and Gehring 1987). $D f(3 L) v_{\text {vin }}^{2}, \quad D f(3 L) v_{\text {vin }}^{3}, \quad D f(3 L) v_{\text {vin }}^{4}, \quad D f(3 L) v_{\text {vin }}^{5}, \quad D f(3 L) v_{\text {vin }}{ }^{6}$, $D f(3 L)_{\text {vin }}{ }^{7}$, and $D f(3 L)$ vin $^{66}$ are deficiencies in the vin regions (Akam et al. 1978; Crosby and Meyerowitz 1986). The smallest deficiency, $D f(3 L) v_{v^{3}}{ }^{3}$, in addition to affecting the development of anal pads and hindgut, also often gave a variable range of other severe developmental aberrations even in trans to the other vin deficiencies. Therefore, we did not use it for further investigation of the phenotype of Trg-deficient embryos. 1(3)183 and neo114 are alleles of 1(3)rsg11 or 1(3)68Ea (Hoogwerf et al. 1988 ), both synonyms for the $c y c A$ gene (Lehner and O'Farrell 1989). 1(3)183 and neo114 do not affect the expression of Trg. Unfortunately, other mutant stocks described in the genetic analysis of the region $68 \mathrm{C} 8$;69B5 (Hoogwerf et al. 1988) have been lost from the stock collections.

\section{Antibodies and probes}

The following antibodies were used in the study: anti-Caudal (Mlodzik and Gehring 1987); anti-Cyclin A (Lehner and O'Farrell 1989|; anti-digoxygenin (Boehringer Mannheim, Germany); anti-Engrailed (4D9; Patel et al. 1989a); anti-Even-skipped (3C10, Patel et al. 1992); anti- $\beta$-galactosidase (Sigma, St. Louis); and anti- $\mathrm{TN}_{1-123}$ (Kispert and Herrmann 1993), the antibody bound specifically to Trg protein in Drosophila embryos [anti$\mathrm{TN}_{1-123}$ did not show any cross-reaction to the Omb protein in the Drosophila embryo that contains a distinct T-domain and is expressed in the optic lobe primordium and in cells of the developing ventral and peripheral nervous system (Poeck et al. 1993)]; anti-Wingless (Van Den Heuvel et al. 1989); biotinylated anti-rabbit-, anti-rat-, and anti-mouse-IgG (Jackson, Bar Harbor).

The $h k b$ cDNA used for the in situ detection of $h k b$ mRNA was a gift from G. Brönner (Brönner and Jäckle 1991) and was isolated as a HindIII-EcoRI fragment from a pNB40 cDNA clone. The tll cDNA was kindly provided by Frank Sprenger (MPI, Tübingen, Germany) and isolated as an EcoRI fragment from a Bluescript cDNA clone. For the detection of $f k h$ RNA we used the $4-\mathrm{kb} X h o l$ fragment containing most of the $f k h$ transcription unit (Weigel et al. 1989a), and for Trg RNA the 3-kb EcoRI fragment of the Trgl cDNA.

\section{Immunohistochemical detection of protein and RNA in Drosophila embryos}

Drosophila embryos were dechorionated with commercial bleach $5 \% \mathrm{NaOCl}$, fixed with $4 \%$ formaldehyde in PBS/heptane and devitellinized by vortexing in heptane/methanol and subsequently in methanol. The immunostaining followed standard protocols of washes and blocking agents, and the bound antibodies were detected histochemically with the Vectastain $\mathrm{ABC}$ kit (Vector Labs, USA) using diaminobenzidine as chromogen. Before the embryos were incubated with the anti-TN 123 antibody, they were treated after the devitellinization with $0.3 \% \mathrm{H}_{2} \mathrm{O}_{2}$ in methanol for $20 \mathrm{~min}$ at room temperature and stored (for a few days to several months) in methanol at $-20^{\circ} \mathrm{C}$. These two steps helped to decrease the background of the immunostaining with anti- $\mathrm{TN}_{1-123}$.

Probes were labeled with digoxygenin-dUTP (Boehringer Mannheim, Germany) and used for in situ hybridization as described by Tautz and Pfeifle (1989).

For photomicrography the embryos were mounted individually either in water-free glycerol (in situ hybridizations) or in Epon Durcupan (Fluka, Switzerland) and were photographed using either Kodak Ektachrome 160T or Agfapan APX 100 film on a Zeiss Axiophot equipped with Zeiss $20 \times$ (n.a. 0.50 ) or $40 \times$ (n.a. 0.75) Plan-Neofluar objectives and differential interference contrast optics. The staging of the embryos followed the descriptions of Foe and Alberts (1983) for nuclear cycles and of Campos-Ortega and Hartenstein (1985) for stages after cellularization.

\section{Handling of Locusta and Tribolium embryos}

Locusta embryos were obtained from a population of $L$. migratoria maintained by the Department of Zoology at the University Tübingen and were kindly provided by Klaus Hartfelder. They were fixed and processed for immunostaining essentially as described by Tear et al. (1990) for Schistocerca, with the following differences. The eggs were dissected in PBS, treated with $0.3 \% \mathrm{H}_{2} \mathrm{O}_{2}$ in methanol for $20 \mathrm{~min}$ at room temperature, postfixed, and stored in methanol at $-20^{\circ} \mathrm{C}$. The staining reaction was performed using $0.2 \mathrm{mg} / \mathrm{ml}$ of diaminobenzidine and $0.003 \% \mathrm{H}_{2} \mathrm{O}_{2}$ in PBS plus $0.1 \%$ Triton $\mathrm{X}-100$. The staging of the locust embryos followed the description by Bentley et al. (1979) for the closely related grasshopper Schistocerca nitens.

Tribolium embryos were obtained from a population of $T$. castaneum maintained by the Department of Zoology at the Ludwig-Maximilian University München and were kindly provided by Reinhard Schröder and Diethard Tautz. They were fixed and processed for immunostaining like Drosophila embryos. The staging of the Tribolium embryos follows the description of Stanley (1965), as summarized by Sokoloff (1972) for the closely related species $T$. confusum, and refers to development at $25^{\circ} \mathrm{C}$.

After immunostaining, both Locusta and Tribolium embryos were dissected from surrounding yolk and membranes in waterfree glycerol and mounted individually in glycerol for microphotography. 


\section{Acknowledgments}

We thank Reinhard Schröder and Diethard Tautz, for an introduction to Tribolium embryology and for sending us the Tribolium embryos. Robert Kelsh taught us the handling of Locusta embryos, which Klaus Hartfelder provided. Jordi Casanova and Robert Kelsh critically read the manuscript. We thank Fabian Haas for technical help, Christiane Nüsslein-Volhard, and Uli Schwarz for support, and Katrin Brenner, Gertrud Scheer, and Sandra Schäfer for assistance with the photographic reproduction of the figures. We are grateful to Günter Brönner, Jordi Casanova, Karin Ekström, Daniel Hartl, Christian Lehner, Kathy Matthews, Roel Nusse, Cahir O'Kane, Nipam Patel, Karsten Sauer, Cristina Stella, and Uwe Walldorf, for sending reagents and fly stocks. We are indebted to E.R. Lozovskaya, R.W. Jones, and D.L. Hartl, for determining the chromosomal map position of the $\mathrm{P} 1$ bacteriophage clone. This work was supported by the Deutsche Forschungsgemeinschaft.

The publication costs of this article were defrayed in part by payment of page charges. This article must therefore be hereby marked "advertisement" in accordance with 18 USC section 1734 solely to indicate this fact.

\section{References}

Akam, M.E., D.B. Roberts, G.P. Richards, and M. Ashburner. 1978. Drosophila: The genetics of two major larval proteins. Cell 13: 215-225.

Anderson, D.T. 1972a. The development of hemimetabolous insects. In Developmental systems: Insects (ed. S.J. Counce and C.H. Waddington), pp. 95-163. Academic Press, London, UK.

1972b. The development of holometabolous insects. In Developmental systems: Insects (ed. S.J. Counce and C.H. Waddington), pp. 165-241. Academic Press, London, UK.

Beddington, R.S.P., P. Rashbass, and V. Wilson. 1992. Brachyury-A gene affecting mouse gastrulation and early organogenesis. Development (Suppl.) ??: 157-165.

Bentley, D., H. Keshishian, M. Shankland, and A. Toroian-Raymond. 1979. Quantitative staging of embryonic development of the grasshopper, Schistocerca nitens. J. Embryol. Exp. Morphol. 54: 47-74.

Berleth, T., M. Burri, G. Thoma, D. Bopp, S. Richstein, G. Frigerio, M. Noll, and C. Nüsslein-Volhard. 1988. The role of localization of bicoid RNA in organizing the anterior pattern of the Drosophila embryo. EMBO f. 7: 1749-1756.

Brönner, G. and H. Jäckle. 1991. Control and function of terminal gap gene activity in the posterior pole region of the Drosophila embryo. Mech. Dev. 35: 205-211.

Brown, N.H. and F.C. Kafatos. 1988. Functional cDNA libraries from Drosophila embryos. I. Mol. Biol. 203: 425-437.

Campos-Ortega, J.A. and V. Hartenstein. 1985. The embryonic development of Drosophila melanogaster. Springer, Berlin, Germany.

Casanova, J. 1990. Pattern formation under the control of the terminal system in the Drosophila embryo. Development 110: $621-628$.

Cavener, D.R. 1987. Comparison of the consensus flanking translational start sites in Drosophila and vertebrates. $\mathrm{Nu}$ cleic Acids Res. 15: 1353-1361.

Celniker, S.E., D.J. Keelan, and E.B. Lewis. 1989. The molecular genetics of the bithorax complex of Drosophila: Characterization of the products of the Abdominal-B domain. Genes \& Dev. 3: 1424-1436.

Church, G.M. and W. Gilbert. 1984. Genomic sequencing. Proc. Natl. Acad. Sci. 81: 1991-1995.
Crosby, M.A. and E.M. Meyerowitz. 1986. Lethal mutations flanking the $68 \mathrm{C}$ glue gene cluster on chromosome 3 of Drosophila melanogaster. Genetics 112: 785-802.

Davis, C.A., D.P. Holmyard, K.J. Millen, and A.L. Joyner. 1991. Examining pattern formation in mouse, chicken and frog embryos with an En-specific antiserum. Development 111: $287-298$.

Engels, W.R., C.R. Preston, P. Thompson, and W.B. Eggleston. 1986. In situ hybridization to Drosophila salivary chromosomes with biotinylated probes and alkaline phosphatase. Focus 8: 6-8.

Foe, V.E. and B.M. Alberts. 1983. Studies of nuclear and cytoplasmic behaviour during the five mitotic cycles that precede gastrulation in Drosophila embryogenesis. J. Cell Sci. 61: $31-70$.

Frohnhöfer, H.G. and C. Nüsslein-Volhard. 1986. Organization of anterior pattern in the Drosophila embryo by the maternal gene bicoid. Nature 324: 120-125.

Gaul, U. and D. Weigel. 1991. Regulation of Krüppel expression in the anlage of the Malpighian tubules in the Drosophila embryo. Mech. Dev. 33: 57-68.

Halpern, M.E., R.K. Ho, C. Walker, and C.B. Kimmel. 1993. Induction of muscle pioneers and floor plate is distinguished by the zebrafish no tail mutation. Cell 75: 99-111.

Harbecke, R. and W. Janning. 1989. The segmentation gene Krüppel of Drosophila melanogaster has homeotic properties. Genes \& Dev. 3: 114-122.

Herrmann, B.G. 1991. Expression pattern of the Brachyury gene in whole-mount $T^{\text {Wis }} / T^{\text {Wis }}$ mutant embryos. Development 113: 913-917.

Herrmann, B.G., S. Labeit, A. Poustka, T.R. King, and H. Lehrach. 1990. Cloning of the $T$ gene required in mesoderm formation in the mouse. Nature 343: 617-622.

Hoogwerf, A.M., M. Akam, and D. Roberts. 1988. A genetic analysis of the rose-gespleten region (68C8-69B5) of Drosophila melanogaster. Genetics 118: 665-670.

Jürgens, G. and D. Weigel. 1988. Terminal versus segmental development in the Drosophila embryo: The role of the homeotic gene fork head. Wilhelm Roux's Arch. Dev. Biol. 197: 345-354.

Karess, R.E. and G.M. Rubin. 1984. Analysis of P transposable element functions in Drosophila. Cell 38: 135-146.

Kispert, A. and B.G. Herrmann. 1993. The Brachyury gene encodes a novel DNA binding protein. EMBO /. 12: 3211-3220.

- 1994. Immunohistochemical analysis of the Brachyury protein in wild-type and mutant mouse embryos. Dev. Biol. 161: 179-193.

Kuziora, M.A. and W. McGinnis. 1988. Autoregulation of a Drosophila homeotic selector gene. Cell 55: 477-485.

Langer-Safer, P.R., M. Levine, and D.C. Ward. 1982. Immunological method for mapping genes on Drosophila polytene chromosomes. Proc. Natl. Acad. Sci. 79: 4381-4385.

Lehner, C.F. and P.H. O'Farrell. 1989. Expression and function of Drosophila Cyclin A during embryonic cell cycle progression. Cell 56: 957-968.

Lehner, C.F., N. Yakubovich, and P.H. O'Farrell. 1991. Exploring the role of Drosophila Cyclin A in the regulation of $\mathrm{S}$ phase. Cold Spring Harbor Symp. Quant. Biol. 51: 465-475.

Macdonald, P.M. and G. Struhl. 1986. A molecular gradient in early Drosophila embryos and its role in specifying the body pattern. Nature 324: 537-545.

McGinnis, W. and R. Krumlauf. 1992. Homeobox genes and axial patterning. Cell 68: 283-302.

McMahon, A.P. 1992. The Wnt family of developmental regulators. Trends Genet. 8: 236-242.

McMahon, A.P., A.L. Joyner, A. Bradley, and J.A. McMahon. 
1992. The midbrain-hindbrain phenotype of Wnt-1-/Wnt$1^{-}$mice results from stepwise deletion of engrailed-expressing cells by 9.5 days postcoitum. Cell 69: 581-595.

Mlodzik, M. and W.J. Gehring. 1987. Expression of the caudal gene in the germ line of Drosophila: Formation of an RNA and protein gradient during early embryogenesis. Cell 48: $465-478$.

O'Kane, C.J. and W.J. Gehring. 1987. Detection in situ of genomic regulatory elements in Drosophila. Proc. Natl. Acad. Sci. 84: 9123-9127.

Ortolani, G. 1957. Il territorio precoce della corda nelle ascidie. Acta Embryol. Morphol. Exp. 1: 33-36.

Patel, N.H., E. Martin-Blanco, K.G. Coleman, S.J. Poole, M.C. Ellis, T.B. Kornberg, and C.S. Goodman. 1989a. Expression of engrailed proteins in arthropods, annelids, and chordates. Cell 58: 955-968.

Patel, N.H., T.B. Kornberg, and C.S. Goodman. 1989b. Expression of engrailed during segmentation in grasshopper and crayfish. Development 107: 201-212.

Patel, N.H., E.E. Ball, and C.S. Goodman. 1992. Changing role of even-skipped during the evolution of insect pattern formation. Nature 357: 339-342.

Pflugfelder, G.O., H. Roth, B. Poeck, S. Kerscher, H. Schwarz, B. Jonschker, and M. Heisenberg. 1992. The lethal(1)optomotor-blind gene of Drosophila melanogaster is a major organizer of optic lobe development: Isolation and characterization of the gene. Proc. Natl. Acad. Sci. 89: 11991203.

Pignoni, F., R.M. Baldarelli, E. Steingrímsson, R.J. Diaz, A. Patapoutian, J.R. Merriam, and J.A. Lengyel. 1990. The Drosophila gene tailless is expressed at the embryonic termini and is a member of the steroid receptor superfamily. Cell 62: 151-163.

Pirrotta, V. 1988. Vectors for P-mediated transformation in Drosophila. In Vectors, a survey of molecular cloning vectors and their uses (ed. R.L. Rodriguez and D.T. Denhardt), pp. 437-456. Butterworth, Boston, MA.

Poeck, B., A. Hofbauer, and G.O. Pflugfelder. 1993. Expression of the Drosophila optomotor-blind gene transcript in neuronal and glial cells of the developing nervous system. Development 117: 1017-1029.

Poelmann, R.E. 1981. The head-process and the formation of the definitive endoderm in the mouse embryo. Anat. Embryol. 162: 41-49.

Reuter, R. 1994. The gene serpent has homeotic properties and specifies endoderm versus ectoderm within the Drosophila gut. Development 120: 1123-1135.

Sanger, F., S. Nicklen, and A.R. Coulson. 1977. DNA sequencing with chain terminating inhibitors. Proc. Natl. Acad. Sci. 74: 5463-5467.

Schulte-Merker, S., R.K. Ho, B.G. Herrmann, and C. NüssleinVolhard. 1992. The protein product of the zebrafish homologue of the mouse $T$ gene is expressed in nuclei of the germ ring and the notochord of the early embryo. Development 116: 1021-1032.

Siewing, R. 1969. Lehrbuch der vergleichenden Entwicklungsgeschichte der Tiere. Verlag Paul Parey, Hamburg/Berlin, Germany.

Skaer, H. 1993. The alimentary canal. In The developmental biology of Drosophila melanogaster (ed. M. Bate and A. Martinez-Arias), pp. 941-1012. Cold Spring Harbor Laboratory, Cold Spring Harbor, New York.

Slack, J.M.W., P.W.H. Holland, and C.F. Graham. 1993. The zootype and the phylotypic stage. Nature 361: 490-492.

Smith, J.C., B.M.J. Price, J.B.A. Green, D. Weigel, and B.G. Herrmann. 1991. Expression of a Xenopus homolog of
Brachyury $(T)$ Is an immediate-early response to mesoderm induction. Cell 67: 79-87.

Smoller, D.A., D. Petrov, and D.L. Hartl. 1991. Characterization of bacteriophage P1 library containing inserts of Drosophila DNA of 75-100 kilobase pairs. Chromosoma 100: 487-494.

Sokoloff, A. 1972. Developmental and post-embryonic studies. In The biology of Tribolium, pp. 163-206. Clarendon Press, Oxford, UK.

Spradling, A.C. 1986. P element-mediated transformation. In Drosophila: A practical approach (ed. D.B. Roberts), pp. 175197. IRL Press, Oxford, UK.

Stanley, M.S.M. 1965. "The development of the confused flour beetle Tribolium confusum Duval." Ph.D. thesis, University of Utah, Salt Lake City, UT.

Strecker, T.R., J.R. Merriam, and J.A. Lengyel. 1988. Graded requirement for the zygotic terminal gene, tailless, in the brain and tail region of the Drosophila embryo. Development 102: 721-734.

Tautz, D. and C. Pfeifle. 1989. A non-radioactive in situ hybridization method for the localization of specific RNAs in Drosophila embryos reveals translational control of the segmentation gene hunchback. Chromosoma 98: 81-85.

Tear, G., M. Akam, and A. Martinez-Arias. 1990. Isolation of an abdominal-A gene from the locust Schistocerca gregaria and its expression during early embryogenesis. Development 110: $915-925$.

Van Den Heuvel, M., R. Nusse, P. Johnston, and P.A. Lawrence. 1989. Distribution of the wingless gene product in Drosophila embryos: A protein involved in cell-cell communication. Cell 59: 739-749.

Weigel, D., G. Jürgens, F. Kuettner, E. Seifert, and H. Jäckle. 1989a. The homeotic gene fork head encodes a nuclear protein and is expressed in the terminal regions of the Drosophila embryo. Cell 57: 645-658.

Weigel, D., H.J. Bellen, G. Jürgens, and H. Jäckle. 1989b. Primordium specific requirement for the homeotic gene fork head in the developing gut of the Drosophila embryo. Wilhelm Roux's Arch. Dev. Biol. 198: 201-210.

Weigel, D., G. Jürgens, M. Klingler, and H. Jäckle. 1990. Two gap genes mediate maternal terminal pattern information in Drosophila. Science 248: 495-498.

Yasuo, H. and N. Satoh. 1994. An ascidian homolog of the mouse Brachyury $(T)$ gene is expressed exclusively in notochord cells at the fate restricted stage. Dev. Growth Differ. 36: 9-18. 


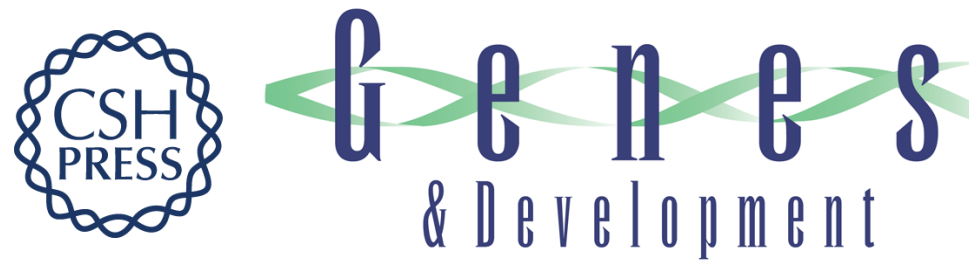

\section{Homologs of the mouse Brachyury gene are involved in the specification of posterior terminal structures in Drosophila, Tribolium, and Locusta.}

A Kispert, B G Herrmann, M Leptin, et al.

Genes Dev. 1994, 8:

Access the most recent version at doi:10.1101/gad.8.18.2137

References This article cites 56 articles, 20 of which can be accessed free at:

http://genesdev.cshlp.org/content/8/18/2137.full.html\#ref-list-1

License

Email Alerting

Service

Receive free email alerts when new articles cite this article - sign up in the box at the top right corner of the article or click here.

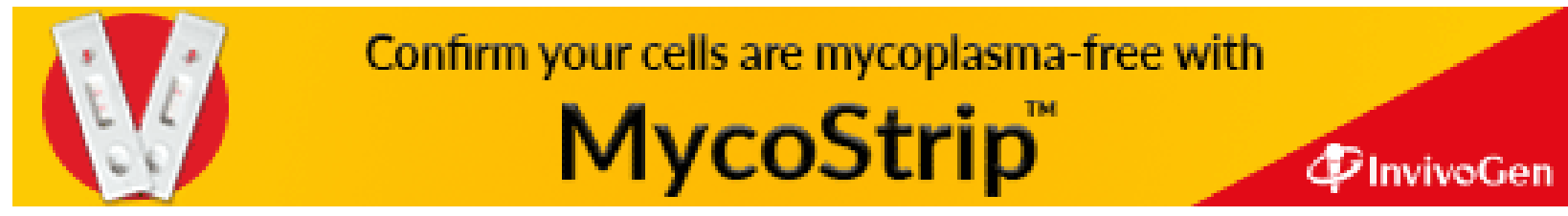

